\title{
Evaluation of the methods to identify patients who may benefit from PARP inhibitor use
}

\author{
Diana Lim ${ }^{1}$ and Joanne Ngeow ${ }^{2,3}$ \\ 'Department of Pathology, National University Health System, Singapore, Singapore \\ 2Lee Kong Chian School of Medicine, Nanyang Technological University, Singapore, Singapore \\ ${ }^{3}$ Cancer Genetics Service, Division of Medical Oncology, National Cancer Centre, Singapore, Singapore
}

Correspondence should be addressed to J Ngeow

Email

Joanne.Ngeow.Yuen.Yie@ singhealth.com.sg

\begin{abstract}
The effectiveness of poly (ADP-ribose) polymerase inhibitors (PARPi) in treating cancers associated with $B R C A 1 / 2$ mutations hinges upon the concept of synthetic lethality and exemplifies the principles of precision medicine. Currently, most clinical trials are recruiting patients based on pathological subtypes or have included BRCA mutation analysis (germ line and/or somatic) as part of the selection criteria. Mounting evidence, however, suggests that these drugs may also be efficacious in tumors with defects in other genes involved in the homologous recombination repair pathway. Advances in molecular profiling techniques together with increased research efforts have led to a better understanding of the molecular aberrations underlying this BRCA-like phenotype and helped broaden the concept of BRCAness. Hence, it is likely that the list of predictive biomarkers for PARPi therapy will increase in future. There is currently no gold standard method of testing for PARPi response and no universal guidelines are in place on how to incorporate biomarker testing into routine clinical diagnostics. In this review, we explore the concept of BRCAness and highlight the different methods that have been used to identify patients who may benefit from the use of these anticancer agents. The identification of predictive biomarkers is crucial in improving patient selection and expanding the clinical applications of PARPi therapy.
\end{abstract}
Key Words
- PARP inhibitors
- BRCA
- BRCAness
- homologous recombination
- biomarkers

\section{Introduction}

The development of novel therapies targeting specific biological pathways has led to a paradigm shift in the way we approach cancer therapeutics. The use of poly (ADP-ribose) polymerase inhibitors (PARPi), with their selective mechanisms of action involving the DNA damage repair pathways, illustrates this strategy. PARPi are being evaluated in clinical trials either as monotherapeutic agents or in combination with other anticancer therapy to improve therapeutic efficacy. The recruitment of patients for some of these trials has been based on molecular and phenotypic evidence of defects in DNA repair, in particular homologous recombination (HR) repair, such as those with germ line $B R C A$ mutations, or included tumor types known to be associated with BRCA mutations, such as basallike or triple-negative breast cancers (TNBC) and highgrade ovarian serous carcinomas (HGOSC). Few studies have included other biomarker analyses as part of their recruitment criteria (Table 1). However, there is increasing evidence to suggest that some patients with tumors less

Published by Bioscientifica Ltd. 


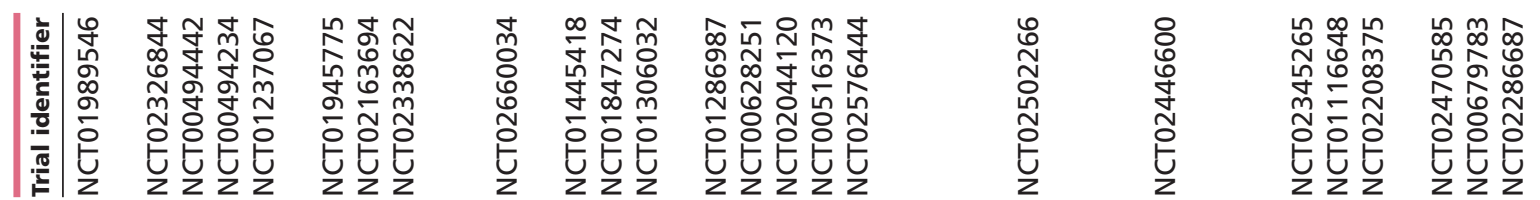
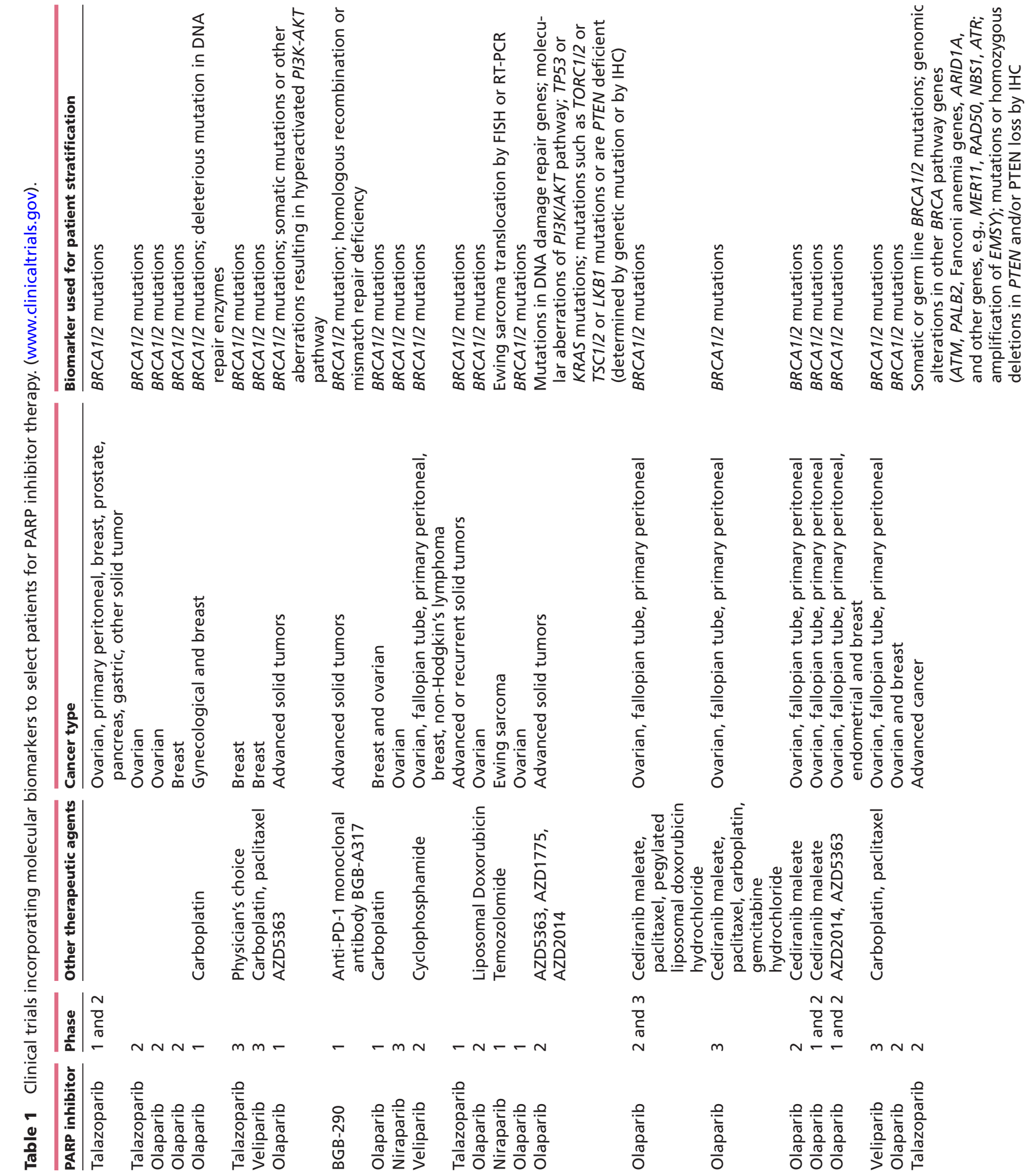

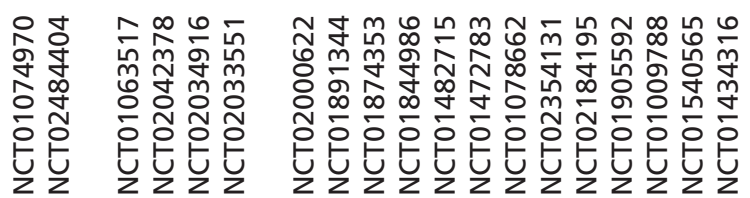

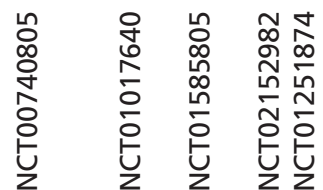
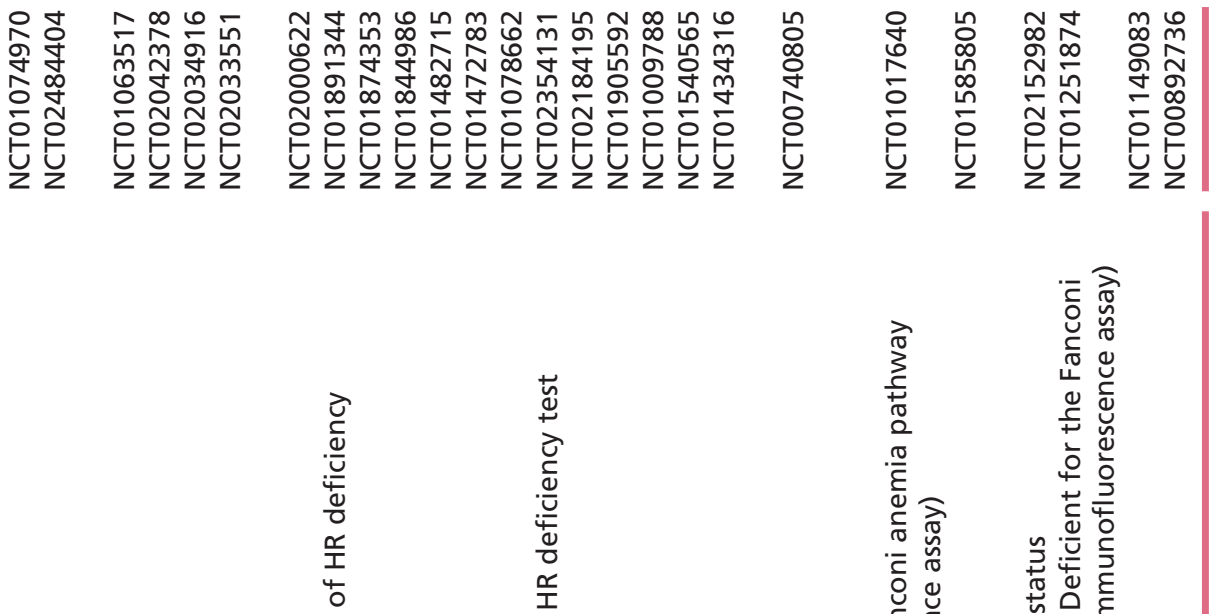

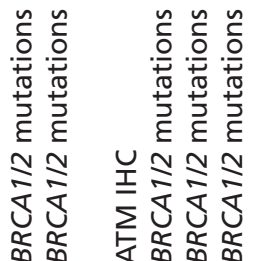
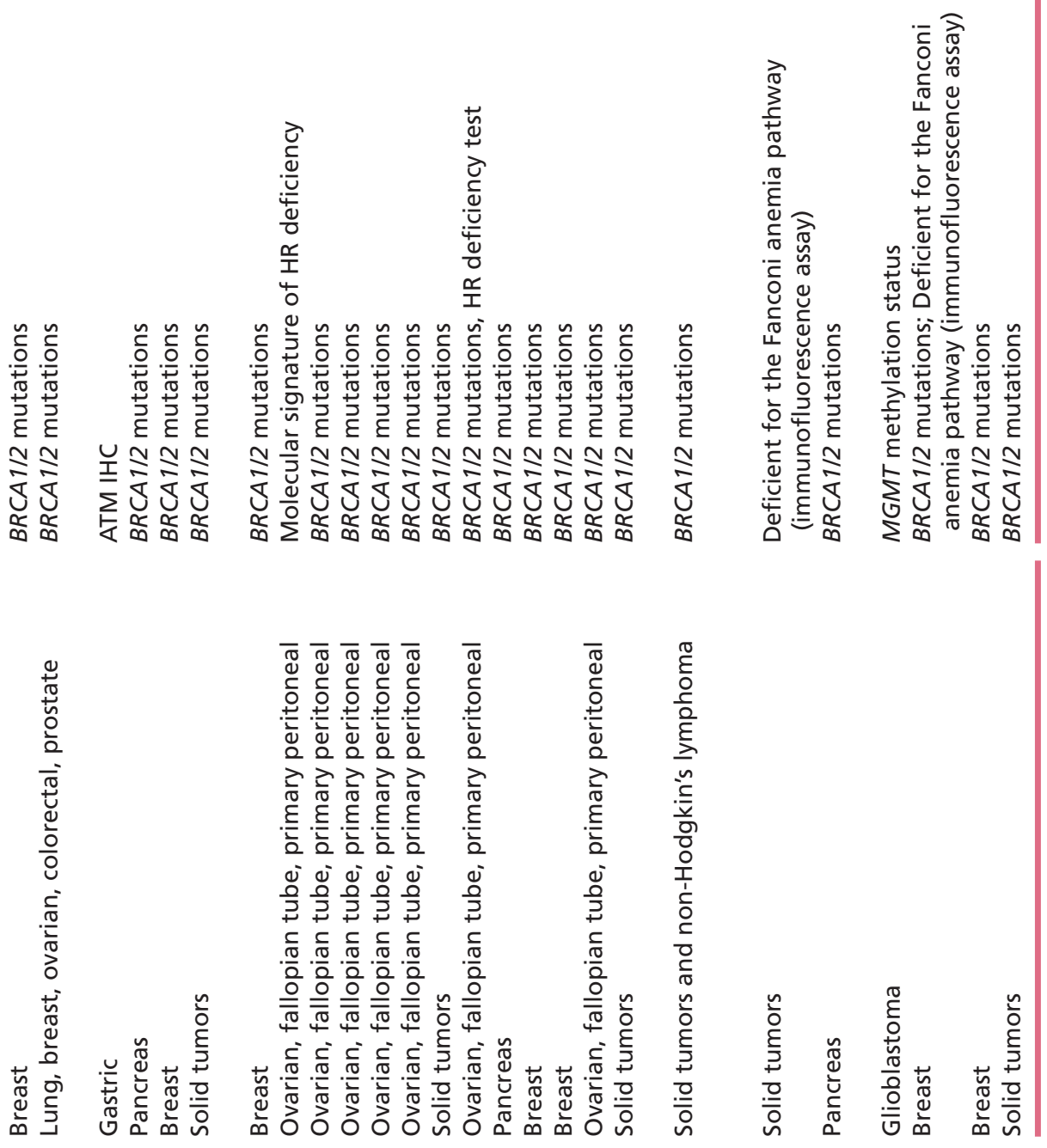

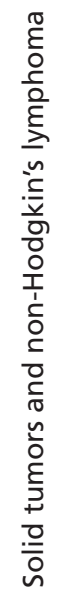

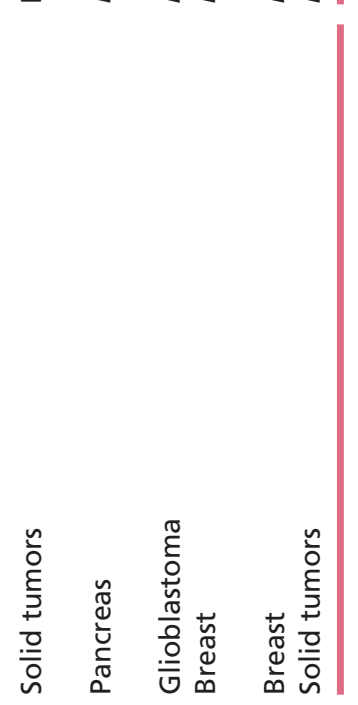

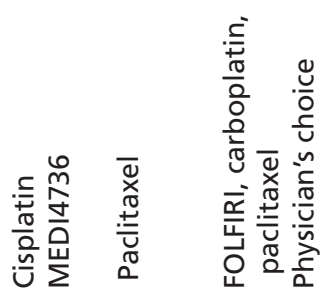
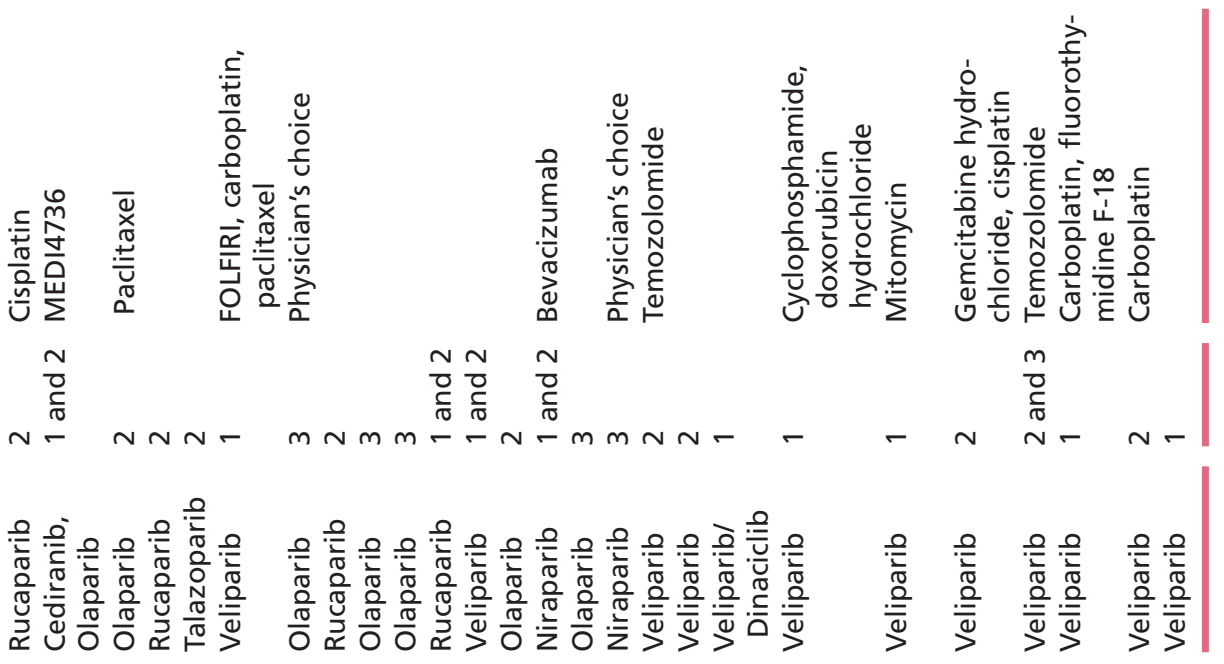
commonly associated with BRCA mutations, such as melanoma, lung, pancreatic, and prostate cancers, may also respond to PARPi therapy (Fong et al. 2009, Paul et al. 2011, O'Sullivan et al. 2014, Kaufman et al. 2015). Furthermore, some tumors in patients without germ line BRCA mutations can share similar clinicopathological and molecular characteristics as those occurring in patients with germ line defects, and these could also potentially response to PARPi-based therapy. Some of these tumors have impaired HR repair pathways that may be attributable to a variety of reasons such as $B R C A 1$ promoter hypermethylation, somatic $B R C A$ mutations, or defects in the other genes involved in HR. Therefore, the utility of PARPi in cancer therapeutics is potentially greater than what was initially envisioned.

In this review, we discuss the concept of 'BRCAness' using examples of emerging mechanisms of regulation of HR and evaluate the various methods that can be used to identify patients who may benefit from PARPi therapy.

\section{DNA damage repair pathways and $B R C A$}

A variety of endogenous and environmental genotoxic insults can affect the integrity of the human genome. Damaged DNA triggers an activation of the cell cycle checkpoint pathways leading to cell cycle arrest and allows for DNA repair to take place. Single-strand breaks (SSBs) are corrected via the base excision repair (BER), nucleotide excision repair (NER), or mismatch repair pathways (Kinsella 2009), whereas double-strand breaks (DSBs) are repaired by HR, which restores the original nucleotide sequence, or processes such as non-homologous end joining (NHEJ) or single-strand annealing (SSA), which lack fidelity to the germ line DNA sequence (Hoeijmakers 2001, Kinsella 2009) (Fig. 1A). These highly complex and intertwined repair mechanisms are orchestrated by a myriad of enzymes to ensure the integrity of DNA, which is imperative for cell survival.
$B R C A 1$ and BRCA2 are tumor suppressor genes involved in the repair of DSBs via HR (D'Andrea \& Grompe 2003). BRCA1 promotes cell cycle arrest in conjunction with p53 and associates with DNA DSBs. HR repair begins with the degradation of one strand of the DNA at the site of damage, creating a stretch of single-stranded DNA. RAD51 molecules then bind to the single-stranded DNA to form filamentous structures. These RAD51 foci promote recognition of homologous sequences on the sister chromatid and catalyze pairing between the complementary bases in the intact chromosome, ultimately leading to template-dependent DNA synthesis (Wu 2008). BRCA1 and BRCA2 play a role in RAD51 loading, together with other components, such as ATM, H2AX, PALB2, RPA, RAD52, and proteins of the Fanconi anemia pathway (Polo \& Jackson 2011). Without functional BRCA1/2, error-prone pathways such as NHEJ are preferentially activated. NHEJ repairs DSBs by ligating the two broken DNA ends without using a homologous DNA sequence to guide repair, often resulting in the introduction of errors at the ligated sites (Davis \& Chen 2013) (Fig. 1B). Mutations that are generated can activate oncogenes or inactivate tumor suppressor genes, ultimately leading to carcinogenesis (Tutt \& Ashworth 2002, Venkitaraman 2002). In addition to DNA repair, $B R C A 1$ also contributes to other cellular processes such as transcriptional regulation and chromatin remodeling (Deng 2006, Savage et al. 2014).

Given their integral roles in maintaining genomic integrity, patients with germ line mutations of BRCA1 and $B R C A 2$ are at an increased risk of developing various malignancies (Venkitaraman 2002). Approximately $5-10 \%$ of breast cancers and $1-18 \%$ of ovarian cancers occur in patients with germ line BRCA mutations (Brody \& Biesecker 1998, Pal et al. 2005, Walsh et al. 2011, Alsop et al. 2012). Other less commonly encountered tumors include gastric, pancreatic, prostate, and lung cancers as well as cutaneous melanoma (Brose et al. 2002, Leongamornlert et al. 2012).

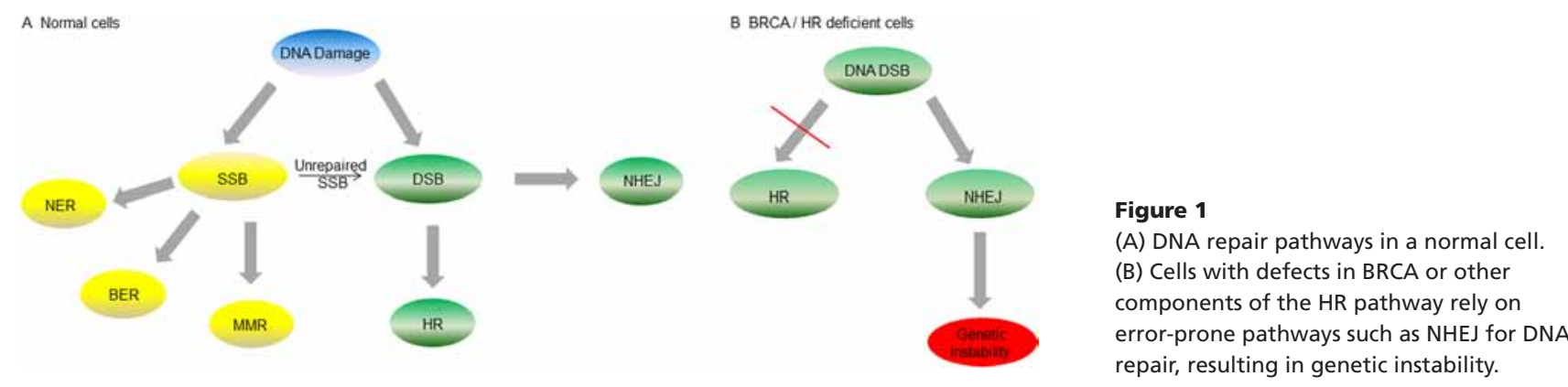




\section{PARP}

The PARP proteins are a superfamily of enzymes engaged in a myriad of cellular functions including transcriptional regulation, DNA repair, cell cycle regulation, inflammation, hypoxic response, spindle pole function, oncogene-related signaling, and cell death (Schreiber et al. 2006, Weaver \& Yang 2013). A change to the nomenclature has been recently proposed as some members of the group catalyze mono- rather than poly(ADP)ribosylation (Hottiger et al. 2010). PARP1 is the most abundant and best characterized member of the family. It has been implicated in several DNA repair mechanisms such as the repair of SSBs via the BER pathway. It recognizes and binds to sites of SSB, after which it catalyzes the transfer of ADP-ribose molecules from NADC to itself and other acceptor proteins to generate long chains of poly(ADP)ribosylated polymers (Haince et al. 2007). This allows for the recruitment of DNA repair proteins such as DNA polymerase $\beta$, DNA ligase III, and scaffolding proteins such as X-ray cross-complementing protein 1 (XRCC1) to sites of SSBs (El-Khamisy et al. 2003, Houtgraaf et al. 2006). PARP1 may also facilitate HR via recruitment of factors such as ATM, Mre11, and Nbs1 to sites of DSBs (Haince et al. 2008) and has been shown to interact with the DNA protein kinase complex involved in NHEJ (Wang et al. 2006) (Fig. 2).

\section{PARP inhibitors and the concept of synthetic lethality}

PARPi are a class of drugs that function as catalytic inhibitors that compete with NADC for the substratebinding site of PARP (Rouleau et al. 2010). They are also postulated to act by 'trapping' PARP at sites of DNA damage, generating a cytotoxic PARP-DNA complex (Murai et al. 2012). Trapped PARP prevents its availability for repair function and secondarily causes replication and transcription fork blockade, resulting in DNA breakage (Helleday 2011). These findings suggest that PARPi have several different modes of action with multiple potential targets in the DNA repair pathway that can result in cancer cell death (Fig. 2).

The early clinical development of PARPi has been focused on targeting cancers associated with BRCA1/2 mutations. This hinges upon the concept of synthetic lethality, whereby a cell harboring one of two gene or protein defects is viable, whereas those containing both defects are not. In this setting, PARP blockade causes replication-associated lesions that cannot be repaired by the defective HR pathway (resulting from BRCA mutations), thereby prompting the activation of compensatory, error-prone DNA repair pathways such as NHEJ that leads to genomic instability, non-viable genetic errors, and, eventually, cell death (Ashworth 2008). This notion was first highlighted in two preclinical studies that

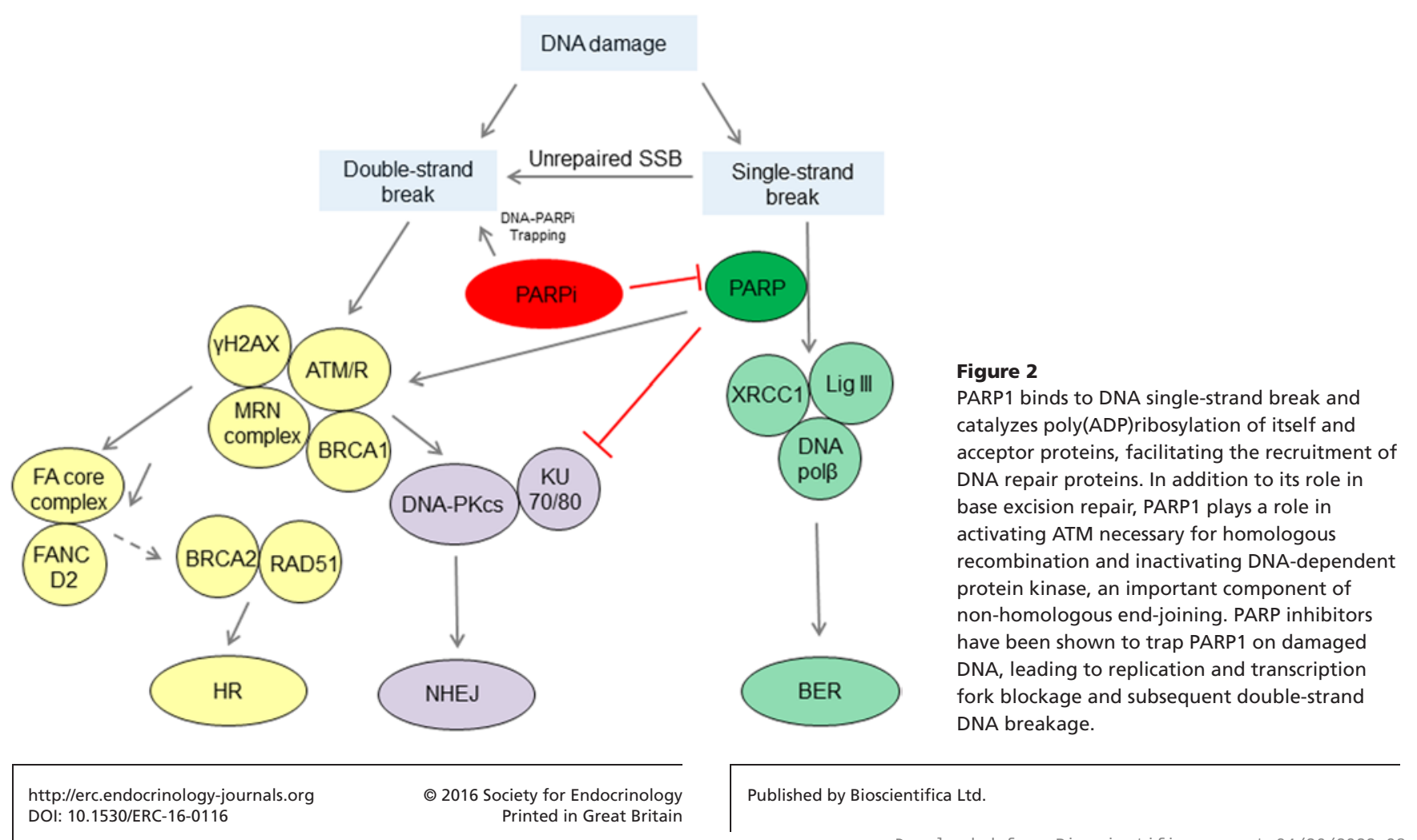


established the sensitivity of $B R C A 1 / 2$ mutant tumor cells to PARPi (Bryant et al. 2005, Farmer et al. 2005) and led to subsequent clinical studies in patients with familial $B R C A 1 / 2$ mutant breast and ovarian tumors, which provided further clinical evidence for the adoption of this therapeutic approach.

The phase 1 trial evaluating single-agent olaparib (AZD2281) in a cohort of patients enriched for BRCA1/2 mutation carriers demonstrated clinical benefit in $12 / 19$ (63\%) patients with objective responses in 9 (47\%) patients (Fong et al. 2009). These led to an expansion cohort comprising 50 BRCA mutation carriers with ovarian, peritoneal, and fallopian tube cancers, of which 13 were platinum refractory, 24 were resistant to platinum, and 13 were sensitive to platinum. These patients exhibited a response rate (according to RECIST criteria or reduction in serum CA125) of $23 \%, 45 \%$, and $69 \%$, respectively, and the efficacy of olaparib correlated with BRCA mutation and platinum sensitivity (Fong et al. 2010). Two subsequent phase 2 trials then established the efficacy of olaparib in familial BRCA1/2 mutant breast and ovarian cancers, with an overall response rates (ORR) of $41 \%$ and $33 \%$ noted in the breast and ovarian cohorts respectively (Audeh et al. 2010, Tutt et al. 2010). In another phase 2 study assessing olaparib as maintenance therapy used in unselected patients with familial or sporadic HGOSC that responded to platinum agents, it was reported that those with germ line or somatic BRCA1/2 mutations demonstrated the best progression-free survival (PFS). Although a statistically significant improvement in overall survival (OS) was not observed in this cohort, the OS data were insufficiently mature to allow for a properly powered comparison between the treatment groups (Ledermann et al. 2012).

In October 2014, the European Medicines Agency (EMA) approved the use of olaparib (Lynparza) as a monotherapy for the maintenance treatment of patients with relapsed, platinum-sensitive epithelial ovarian, fallopian tube, or primary peritoneal cancer with BRCA1/2 mutations. This was followed 2 months later by an approval by the US Food and Drug Administration (FDA) for the use of Lynparza as a monotherapy for the treatment of patients with deleterious germ line $B R C A$-mutated advanced ovarian cancer who have been treated with three or more prior lines of chemotherapy (Kim et al. 2015) based on the findings of a multicenter phase 2 study (Kaufman et al. 2015). This approval was granted together with a companion in vitro diagnostic assay, BRACAnalysis CDX (Myriad Genetics, Inc, Salt Lake
City, UT, USA), which is performed only at the Myriad Genetic Laboratories. The assay allows for the qualitative detection and classification of variants in the protein coding regions and intron/exon boundaries of BRCA1 and $B R C A 2$ using genomic DNA derived from whole blood specimens. Single-nucleotide variants and small insertions and deletions (indels) are identified by PCR and Sanger sequencing, whereas large genomic rearrangements such as deletions and duplications are detected using a multiplex PCR assay. Detected variants are classified into one of the five categories: deleterious mutation, suspected deleterious mutation, variant of uncertain significance, favor polymorphism, and polymorphism. As the FDA did not review the hereditary implications of $B R C A$ testing in this setting, BRACAnalysis CDx should not be regarded as a surrogate screening test for hereditary cancer (Gunderson \& Moore 2015, Kim et al. 2015).

\section{BRCAness}

Although PARPi have been shown to be effective in patients with germ line BRCA1/2 mutations, evidence suggests that they may also be of benefit in the treatment of cancers with defects in other components of the DNA damage repair pathways. The concept of 'BRCAness' was introduced to describe the clinical and biological features that some sporadic tumors share with those harboring germ line $B R C A 1 / 2$ mutations. This not only includes similar histomorphological features such as basal-like phenotype in breast cancers or high-grade serous morphology in ovarian cancers but also similar immunophenotypic profile (e.g., triple-negative breast cancers), drug sensitivity (e.g., to platinum agents and PARPi), as well as disease prognosis (Turner et al. 2004, Tan et al. 2008) (Fig. 3). This BRCAness phenotype may be attributed in part to defective HR secondary to several mechanisms, including hypermethylation of the BRCA1 promoter (Baldwin et al. 2000, Esteller et al. 2000, Geisler et al. 2002, Teodoridis et al. 2005), somatic mutations of BRCA1/2 (Foster et al. 1996, Geisler et al. 2002, Hilton et al. 2002, Hennessy et al. 2010, Ledermann et al. 2014), EMSY amplification (Hughes-Davies et al. 2003), or loss-of-function mutations involving other HR pathway genes, including ATM, ATR, BARD1, BRIP1, MRE11A, PALB2, RAD50, RAD51D, RAD54, NBS1, CHEK1, and CHEK2, as well as components of the Fanconi anemia repair pathway (Hughes-Davies et al. 2003, Taniguchi et al. 2003, Venkitaraman 2003, Dedes et al. 2011, Loveday et al. 2011, Rigakos \& Razis 2012, Strom \& Helleday 2012, Lord \& Ashworth 2016).

Published by Bioscientifica Ltd 


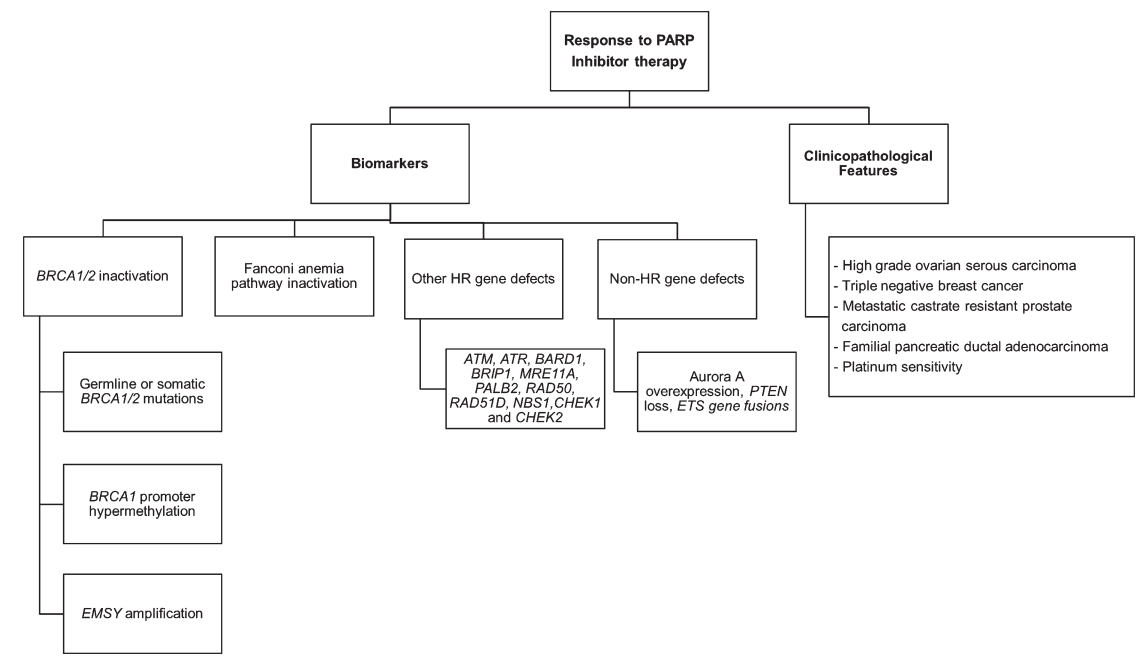

Figure 3

Clinicopathological features and molecular biomarkers associated with response to PARP inhibitor therapy.

Clinical evidence indicates that tumors with this phenotype can respond to PARP inhibition. In a phase 2 trial of olaparib, which included both BRCA1/2-mutated and wild-type patients with breast cancer and HGOSC, non-BRCA mutant patients who had platinum-sensitive HGOSC showed an ORR of 50\% (Gelmon et al. 2011). A $17 \%$ response rate was also observed in the platinumresistant cohort without $B R C A 1 / 2$ mutation, suggesting an incomplete crossover of platinum sensitivity and PARPi response. Similarly, in a phase 1 study evaluating niraparib in advanced solid tumors enriched for sporadic cancers associated with non-BRCA HR repair defects, three patients with partial response and four with stable disease were identified (Schelman et al. 2011).

\section{Resistance to PARP inhibition}

Conversely, not all patients with mutations in $B R C A 1 / 2$ or genes associated with BRCAness will response to PARPi, as different mutations may have differing effects on HR repair function and sensitivities to PARP inhibition. Mouse model studies have shown that a missense mutation in the RING domain of BRCA1, C61G, reduces the ability of BRCA1 to interact with its heterodimerization partner, BRCA1associated RING domain protein 1 (BARD1), but does not result in PARPi or platinum salt sensitivity (Jaspers et al. 2013). The Consortium of Investigators of Modifiers of BRCA1/2 (CIMBA) assessed cancer incidence in more than $31,000 B R C A 1 / 2$ mutation carriers and reported that the risk of developing breast or ovarian cancer is determined by the position and type of mutation, with mutations in different regions of both genes associated with differing risk levels (Rebbeck et al. 2015). In comparison, there is very limited understanding of what factors may affect
PARPi responses in the setting of other BRCAness genes. It is also likely that the therapeutic implications may differ in different cancer types, further reinforcing the importance of the context in which BRCA and other HR-related genes function in these malignancies.

Differences in treatment response could also result from the development of resistance, and it has been postulated that mechanisms of drug resistance may differ depending on which BRCAness gene is involved (Edwards et al. 2008, Sakai et al. 2008, Patch et al. 2015). Several mechanisms leading to both intrinsic and acquired resistance to PARP inhibitors have been identified. These include secondary mutations that restore the open reading frame and the original function of $B R C A 2$, thereby reinstating HR competence (Edwards et al. 2008, Sakai et al. 2008). Preclinical and clinical evidence indicates that genomic instability promoted by PARPi in HR-deficient cells may result in secondary mutations in the mutated $B R C A 1 / 2$ gene with restoration of functional protein expression and induction of PARPi resistance (Edwards et al. 2008, Sakai et al. 2009, Norquist et al. 2011, Barber et al. 2013).

Other mechanisms of resistance to PARPi include restoration of $\mathrm{HR}$ in $B R C A 1$ mutant cells via either inactivation of mitotic arrest-deficient 2-like protein 2 (MAD2L2) or P53-binding protein 1 (53BP1) (Bunting et al. 2010), both of which are involved in controlling DNA resection at DSBs (Patch et al. 2015, Xu et al. 2015). In vitro and in vivo experiments have shown that loss of 53BP1 restores $\mathrm{HR}$ and renders BRCA1-deficient cells resistant to PARP inhibition (Bouwman et al. 2010, Bunting et al. 2010). Decreased 53BP1 levels have also been detected in BRCA1 mutant ovarian carcinoma patients that developed secondary resistance to platinum agents and

Published by Bioscientifica Ltd 
PARPi (Johnson et al. 2013, Patch et al. 2015). Thus, 53BP1 expression may be of use in predicting response to PARPi.

\section{Biomarker testing}

Despite a greater understanding of the molecular aberrations associated with a BRCA-like phenotype, the identification of patients who will respond to therapy still presents considerable challenges. This is due to the lack of a unifying morphological phenotype, the varied components of the repair pathways, and numerous potential mechanisms of drug resistance. The development of predictive biomarkers and diagnostic assays that will allow for robust patient selection remains an important area of research. At present, there is no gold standard method to reliably identify such patients for PARPi therapy, although various biomarkers have been explored, including testing for BRCA mutations (both germ line and somatic) or genetic defects in the other genes involved in HR.

\section{Germ line BRCA mutations}

$B R C A 1 / 2$ germ line variant screening has traditionally been performed using a combination of Sanger sequencing and multiplex ligation-dependent probe amplification (MLPA). Sanger sequencing is able to detect small variants such as the deletion or insertion of single bases, whereas MLPA identifies large gene rearrangements, such as the deletion or duplication of one or more exons. However, these methods are time consuming and costly (Ruiz et al. 2014) and they generally require a significant input of goodquality DNA. The adoption of next-generation sequencing (NGS) has allowed for massive parallel sequencing of multiple genes, ranging from multi-gene panels to whole exomes and genomes (Feliubadalo et al. 2013, Hernan et al. 2012). In comparison to direct Sanger sequencing, NGS allows for faster, more efficient, high-throughput testing at a considerably lower cost (Harismendy et al. 2009). With NGS, results can consistently be provided within a clinically useful time frame, allowing their incorporation into treatment decisions. However, these sequencing techniques have limited ability to detect structural gene rearrangements and may need to be supplemented by other methods such as MLPA to ensure that the full spectrum of genetic aberrations are accounted for (Patch et al. 2015). Furthermore, most NGS platforms require substantial bioinformatic input for the analysis and interpretation of sequencing data, and this has been a considerable hurdle for laboratories considering switching to NGS. Wider availability of more affordable testing may also result in a greater volume of tests performed, placing an increased need for better integration between oncology and clinical genetic services (George 2015).

\section{$B R C A$ inactivation in sporadic cancers}

Another important mechanism of BRCAness is the presence of somatic mutations in $B R C A 1 / 2$, which has been identified in some sporadic ovarian and breast cancers. Hennessy and colleagues performed BRCA1/2 sequencing using snap-frozen tumor tissue from 235 unselected ovarian cancers and identified mutations in 19\% (31 BRCA1 and 13 BRCA2 mutations) of tumors with the vast majority occurring in high-grade serous carcinomas. In 28 samples, where germ line DNA was also available, $42.9 \%$ of the BRCA1 mutations and $28.6 \%$ of the BRCA2 mutations were found to be purely somatic. $B R C A 1 / 2$ mutations were associated with improved PFS after platinum-based chemotherapy in univariate and multivariate analyses. BRCA1/2 deficiency, defined as $B R C A 1 / 2$ mutations or expression loss, was present in $30 \%$ of tumors and was also significantly associated with PFS (Hennessy et al. 2010). Using targeted capture and massively parallel genomic sequencing, Pennington et al. identified germ line (24\%) and somatic (9\%) mutations in one or more of 13 HR genes, including BRCA1, BRCA2, ATM, BARD1, BRIP1, CHEK1, CHEK2, FAM175A, MRE11A, NBN, PALB2, RAD51C, and $R A D 51 D$, in patients with ovarian, fallopian tube, and peritoneal carcinomas. Interestingly, both serous and non-serous carcinomas were found to have comparable HR mutation rates. The presence of germ line and somatic HR mutations was highly predictive of primary platinum sensitivity $(P=0.0002)$ and improved overall survival $(P=0.0006)$, with a median overall survival of 66 and 59 months in cases with germ line or somatic HR mutations, respectively, compared with 41 months for those with no HR mutations (Pennington et al. 2014). Similarly, the Cancer Genome Atlas (TCGA) reported that up to $6.3 \%$ of HGOSC harbor somatic mutations in BRCA1/2 (Cancer Genome Atlas Research Network 2011).

Somatic BRCA1/2 mutations have also been identified in breast cancers albeit in smaller numbers. In the TCGA cohort, approximately $20 \%$ of TNBCs had either germ line $(N=12)$ or somatic $(N=8) B R C A 1 / 2$ mutations, whereas in another study, one of 77 TNBC was found to harbor a somatic BRCA mutation (Gonzalez-Angulo et al. 2011). These findings highlight the need to evaluate tumors

Published by Bioscientifica Ltd. 
for somatic disruption of the $B R C A$ pathway in patients lacking germ line $B R C A$ mutations.

There are, however, several challenges to be met in trying to detect somatic BRCA mutations in tumor samples. First, some specimens may be small (e.g., biopsies), with limited DNA yield that may be of poor quality, thus constraining the analysis that can be undertaken. This poses a significant challenge with respect to accurate detection, characterization, and interpretation of sequence variants in $B R C A 1 / 2$. Second, tumor samples are also histologically heterogeneous, and DNA derived from tumor tissue will invariably contain admixed DNA from normal cells. Consequently, methods for somatic mutation detection have to be able to detect DNA changes that may be present in a low proportion of the total DNA isolated from the sample. Traditional Sanger sequencing techniques for BRCA testing generally require good-quality, high-molecular-weight input DNA of high yield, usually extracted from blood, and may not be suitable for analysis of formalin-fixed paraffinembedded (FFPE) tumor tissue, where the extracted DNA is typically of poorer quality, more fragmented, and of low yield. In addition, Sanger sequencing may not be sensitive enough to detect low-level somatic changes present in tumor tissue. In comparison, NGS methods require less input DNA, as the reactions can be highly multiplexed and have the potential to detect variants at low allele frequency (Sims et al. 2014); thus, the use of NGS may offer a potential solution to this challenging type of analysis (Ellison et al. 2015). Lastly, formalin fixation can lead to deamination and cross-linkage of DNA, resulting in sequencing artifacts. This issue may be resolved by duplicate analysis starting from the original DNA, as artifacts will generally be randomly distributed and should not be present in both samples.

Epigenetic mechanisms of gene inactivation may occur as an alternative to genetic mutation in the silencing of BRCA (Jones \& Baylin 2002). Aberrant methylation of cytosine residues in $\mathrm{CpG}$ dinucleotides in the promoter region results in transcriptional silencing of the gene. Aberrant methylation of the BRCA1 promoter is identified in up to $14 \%$ of sporadic breast cancers (Catteau et al. 1999, Esteller et al. 2000, Rice et al. 2000) and 31\% of ovarian cancers (Catteau et al. 1999, Baldwin et al. 2000, Esteller et al. 2000, Geisler et al. 2002). BRCA1 methylation is associated with decreased BRCA1 transcript in breast cancer (Esteller et al. 2000, Rice et al. 2000) and with decreased/absent protein expression by immunohistochemical analysis in breast (Matros et al. 2005) and ovarian cancers (Baldwin et al.
2000). Evidence to support the etiological importance of BRCA1 methylation is derived from the similarities in morphological, immunohistochemical, and molecular phenotypes between these tumors and familial BRCA1 cancers. For example, BRCA1-methylated breast cancers have a higher histological grade, are more likely to be ER negative, lack ERBB2 amplification, and frequently show amplification of $c-M Y C$, similar to familial BRCA1 cancers (Catteau et al. 1999, Esteller et al. 2000, Grushko et al. 2004). Data from expression microarrays also suggest that the expression profile of sporadic tumors with BRCA1 methylation is similar to those with germ line BRCA1 mutation (Sorlie et al. 2003). Thus, patients with hypermethylated $B R C A 1$ may benefit from PARPi therapy, although it is possible that they may not demonstrate the same degree of drug sensitivity as patients with germ line BRCA mutations (Cancer Genome Atlas Research Network 2011). This was alluded to in a study by Ruscito and colleagues, who showed that even though $14.8 \%$ of HGOSC had hypermethylation in a selected region of the BRCA1 promoter, this had no effect on the PFS or OS rate in patients treated with conventional chemotherapy (Ruscito et al. 2014). Methylation status of the BRCA genes may be investigated using a variety of methods including direct bisulfite sequencing, methylationspecific PCR, methylation microarrays, pyrosequencing, and NGS, the choice of which would be dependent on factors such as the type of biological samples and tumor content present (Ibragimova \& Cairns 2011).

In contrast to $B R C A 1$, the $B R C A 2$ promoter is rarely hypermethylated; however, transcriptional down-regulation of $B R C A 2$ is frequently associated with amplification of the EMSY gene, which has been reported in up to $13 \%$ of sporadic breast cancers and $17 \%$ of high-grade sporadic ovarian cancers (Hughes-Davies et al. 2003).

\section{BRCA immunohistochemistry}

Absent immunohistochemical (IHC) expression of BRCA1 can be attributed to a variety of mechanisms including germ line or somatic mutation and promoter hypermethylation and therefore may have utility as a surrogate marker for BRCA1 loss. A study evaluating IHC expression and mutational status of BRCA1 in HGOSC reported that IHC was an accurate and highly reproducible method for detecting germ line, somatic, or epigenetic mechanisms of BRCA1 loss. These findings were consistent with results from other studies examining the use of BRCA1 IHC (Byrne et al. 2000, Vaz et al. 2007, Garg et al. 2013).

Published by Bioscientifica Ltd 
Lesnock et al. also reported that decreased BRCA1 expression was associated with a 36-month survival improvement in patients with ovarian carcinoma treated with cisplatin-based intraperitoneal chemotherapy and thus may be a useful biomarker for selecting patients for this form of therapy (Lesnock et al. 2013).

The other advantages of using IHC is that it is a relatively simple and cost-efficient technique that is performed in most pathology laboratories and can be easily repeated, thus allowing its use as a dynamic biomarker throughout the disease course as methylation status changes or secondary gain-of-function mutations accumulate. These findings support the incorporation of BRCA1 IHC testing for patient selection in clinical trials, particularly in the setting of recurrent disease (Meisel et al. 2014).

\section{Detecting BRCAness}

Relying solely on BRCA mutations to drive PARP-directed therapeutics will undoubtedly exclude a significant proportion of patients with defects in other HR genes who may also benefit from PARPi therapy. The major challenge lies in the development and validation of robust assays to identify or even quantify HR deficiencies in tumor samples so as to improve patient selection for PARPi therapy (Do \& Chen 2013).

The development of new molecular profiling techniques has allowed for more rapid and in-depth characterization of the frequency of HR gene mutations in different cancer types (Cancer Genome Atlas Research Network 2011, Patch et al. 2015). Data from the TCGA study that profiled 489 HGOSC using a combination of whole exome sequencing, mRNA, microRNA, methylome, and DNA copy number profiling identified alterations in at least one HR-modulating gene in about $50 \%$ of tumors. These included germ line BRCA1 (9\%) or BRCA2 (8\%) mutations, somatic mutations of $B R C A 1 / 2$ (3\%), amplification of EMSY (13\%), PTEN mutations (7\%), hypermethylation of the RAD51 homolog RAD51C (3\%), mutations in $A T M$ or ATR (2\%), and FANC mutations (5\%) (Cancer Genome Atlas Research Network 2011). In another study, whole-genome profiling of 114 tumor samples from 92 patients with HGOSC was performed and again, either germ line or somatic defects in BRCAnessassociated genes, were identified in approximately half of the samples analyzed, including mutations involving BRCA1 (promoter hypermethylation was also observed), BRCA2, PTEN, RAD51B, BRIP1 (also known as FANCJ), CHEK2, FANCI, and RAD51C (Patch et al. 2015). Using targeted capture and massively parallel genomic sequencing, Pennington et al. assessed 390 ovarian carcinomas for germ line and somatic loss-offunction mutations in 30 genes, including $B R C A 1 / 2$, and 11 other genes in the HR pathway (Pennington et al. 2014). Almost $1 / 3$ of these tumors were found to have deleterious germ line (24\%) and/or somatic (9\%) mutations in at least one of the 13 HR genes (BRCA1, BRCA2, ATM, BARD1, BRIP1, CHEK1, CHEK2, FAM175A, $M R E 11 A, N B N, P A L B 2, R A D 51 C$, and RAD51), and the presence of these mutations was predictive of primary platinum sensitivity and improved OS (Pennington et al. 2014).

Other malignancies such as breast, prostate, and pancreatic cancers can also exhibit defects in HR-modulating genes. Data from the TCGA analysis of 507 breast cancer patients revealed the presence of germ line mutations in BRCA1, BRCA2, ATM, BRIP1, CHEK2, NBS1, PTEN, or RAD51C in 47 patients and $20 \%$ of TNBC had either germ line or somatic BRCA1/2 mutations (Cancer Genome Atlas Research Network 2012). Using panel sequencing, Beltran et al. reported that $12 \%$ and $8 \%$ castration-resistant prostate cancer (CRPC) harbor BRCA2 and ATM mutations (Beltran et al. 2013), respectively, whereas whole exome and transcriptome profiling of 150 metastatic CRPC revealed the presence of at least one mutation in a BRCAness-associated gene in more than 19\% of tumors (Robinson et al. 2015). Data from a phase 2 clinical trial assessing the efficacy of olaparib in the treatment of metastatic CRPC showed that $88 \%$ of patients with homozygous deletions and/or deleterious mutations in a HR repair gene responded to olaparib (Mateo et al. 2015). Similarly, whole-genome and whole-exome sequencing of 100 pancreatic ductal adenocarcinoma samples demonstrated that $24 \%$ possessed either a germ line or a somatic mutation in $B R C A 1, B R C A 2$, or PALB2, whereas $8 \%$ had ATM mutations (Biankin et al. 2012).

Results from these studies support the use of massively parallel sequencing analysis in prospectively designed trials for the selection of patients likely to respond to PARP inhibition. The heterogeneous genetic profile of these tumors make them ideal candidates for panel testing, where comprehensive analysis of multiple genes are performed in parallel. This approach shows clear advantages over sequential testing of multiple genes, which is costly, requires a larger input of DNA, and cannot be realistically performed in a clinically relevant time frame. However, one of the

Published by Bioscientifica Ltd 
major difficulties encountered when using panel testing is the reporting of genetic mutations for which no clear evidence of a causal link exist (Pennington et al. 2014). Determining which of the mutations identified are actually pathogenic and how other variants should be reported will be issues that have to be considered when adopting these sequencing techniques.

It can be further argued that targeted genotyping assays, even when using custom panels, may prove to be inadequate, considering the extensive repertoire of genes involved in DNA repair response and the heterogeneous nature of their genetic/epigenetic inactivation. Therefore, array-based strategies, such as gene expression arrays, have been used to identify gene expression patterns characteristic of defects in the HR pathway, whereas comparative genomic hybridization (CGH) arrays have been utilized to identify patterns characteristic of the genomic instability inherent in BRCAness, as well as to identify specific genomic changes selected for in these tumors.

\section{Gene expression signatures}

Using previously published gene expression data from familial and sporadic ovarian cancers, a group of investigators identified a $B R C A$-like 60-gene signature profile, which was initially validated in ten tumor biopsies from six patients with germ line BRCA1/2 mutations and then in 70 patients with sporadic ovarian cancers, where it was shown to correlate with responsiveness to platinum agents and PARPi. In addition, this 'BRCAness' profile correlated with the ability to form RAD51 foci in BRCA2-mutated pancreatic cancer cell line Capan-1 and was also able to predict for PARPi sensitivity, suggesting that the profile may be detecting a pattern of gene expression that more globally reflects the status of HR, independent of cell lineage (Konstantinopoulos et al. 2010).

The use of similar gene expression profiling approaches has also allowed for the classification of breast cancers. Familial BRCA1 mutant tumors were identified to segregate strongly with basal-type sporadic cancers (Sorlie et al. 2003), indicating that basal-type sporadic tumors and familial BRCA1 mutant tumors could have similar etiologies. Larsen and colleagues analyzed 55 familial BRCA1/2 mutant and 128 sporadic breast tumors to derive a transcriptional signature that was able to predict $B R C A$ mutant cancers in an independent data set (Larsen et al. 2013). Other investigators have also used transcriptional profiles derived from cell lines with either known HR gene defects (Daemen et al. 2012, Peng et al. 2014) or PARPi sensitivity to generate BRCAness signatures.

\section{Mutational signatures}

Impaired DNA repair results in genomic alterations in tumors and contributes to genomic scars that may allow tumors to be molecularly stratified. Evidence suggests that HR-deficient tumors have a unique mutation signature that results from the use of error-prone DSB repair mechanisms (Tutt et al. 2001, Xia et al. 2001). Stratton and colleagues performed a meta-analysis using sequence data from more than 7000 cancers and identified 20 distinct, conserved mutation signatures across a wide variety of tumor types. A signature, characterized by the presence of relatively small deletions (up to $50 \mathrm{bp}$ ), was strongly associated with BRCA1/2 mutations in breast, ovarian, and pancreatic cancers. Interestingly, a subset of tumors lacking BRCA1/2 mutations also exhibited this signature, suggesting the presence of other DNA repair defects in these neoplasms (Alexandrov et al. 2013). Indeed, many of these mutation signatures associated with $B R C A$ mutant tumors, which are often defined by the frequency of specific types of structural rearrangement, can also be found in sporadic tumors. Importantly, these signatures may correlate with response to PARPi therapy (Watkins et al. 2014) and therefore could be used to identify tumors with a BRCAness phenotype. Various high-throughput genomic profiling techniques including array CGH and single-nucleotide polymorphism (SNP) profiling have been used to identify these structural rearrangements.

Array CGH is a technique that assesses DNA copy number changes, such as amplification and deletion, by hybridizing labeled tumor DNA with differently labeled normal control DNA to metaphase chromosomes. Genomic profiling of breast cancers by aCGH identified a $B R C A$ profile that was $91 \%$ accurate in distinguishing $B R C A$-mutated cancers from sporadic, non-hereditary cancers (Joosse et al. 2009). In this study, two of 48 hereditary but non-BRCA-mutated cancers were found to be $B R C A$-like based on 191 discriminatory features. One of these cases had methylation of BRCA1. These investigators then developed a $B R C A 2$ classifier using the same technique, and this showed $89 \%$ sensitivity and $84 \%$ specificity when applied to the validation cohort. A similar approach was used to stratify patients with breast cancer into four distinct subgroups: simple-profile, BRCA1-related, BRCA2-related, and genomic instabilityhigh group 3 (GII-high-III) (Stefansson et al. 2009).

Published by Bioscientifica Ltd 
The BRCA1/2-related cancers showed several large regions of genomic gains or deletions, which was also noted in sporadic cancers within the GII-high-III group, suggesting that these sporadic breast cancers may also harbor defects in HR that could render them sensitive to PARPi therapy. aCGH has also been used to reveal patterns of copy number changes in BRCA1/2 mutant breast tumors that was predictive of a favorable response to highdose carboplatin-based chemotherapy in sporadically occurring TNBC or ER+/HER2- tumors (Lips et al. 2011b, Vollebergh et al. 2011, 2014).

Lips et al. further utilized their aCGH-based classifier of BRCA1-mutated breast cancers to establish a MLPA assay, capable of identifying patients with both BRCA1-mutated tumors and sporadic cancers with a $B R C A 1$-like genomic profile, which had significantly better recurrence-free survival when treated with alkylating chemotherapy (Lips et al. 2011a). MLPA is a method based on amplification and relative quantification of the ligated adjacent probes, which can target up to 50 different genomic regions that show diagnostically or clinically significant copy number changes in patient samples. It is a rapid, cost-efficient method that requires only a small amount of input DNA that can easily be obtained from FFPE specimens and therefore may be more suitable than aCGH for routine clinical application. As the MLPA assay can identify BRCA1-deficient breast cancer patients, this method could be applied both for clinical genetic testing and as a predictor of sensitivity to agents such as PARPi. In the clinical genetic setting, the classifier could be used in addition to conventional BRCA1 mutation testing, as a tool to classify $B R C A 1$ variants of unknown significance or to identify potential BRCA1 mutations other than the mutations that are currently screened for (Lips et al. 2011a). However, compared with aCGH, the assay only interrogates a limited number of genomic loci, thus potentially limiting its use as a discovery platform.

SNP analysis has been used to develop allelic imbalance assays that are associated with a BRCAness profile (Abkevich et al. 2012, Birkbak et al. 2012, Wang et al. 2012, Timms et al. 2014, Marquard et al. 2015). Tutt et al. profiled 126 TNBC using the genome-wide Affymetrix SNP 6.0 array and demonstrated that allelic imbalanced copy number aberrations (AiCNA) were more prevalent in tumors that responded to platinum agents (Watkins et al. 2015). Timms and colleagues from Myriad Genetics Inc. used SNP profiling to develop a HR deficiency (HRD) assay, which combines three different DNA-based metrics of genomic instability: loss of heterozygosity, telomeric allelic imbalance, and large-scale state transitions, from which a HRD score could then be calculated. The HRD score was reported to be predictive of response to platinum-based chemotherapy and/or PARPi in patients with TNBC or BRCA1/2 mutation-associated breast cancer and high-grade ovarian carcinomas, and also identified responders lacking a deleterious BRCA1/2 mutation (Timms et al. 2014, Brown 2015, Wilcoxen KM 2015, Telli et al. 2016). The assay can be performed using DNA extracted from FFPE tumor tissue and thus can be translated into a clinical setting.

The utility of these mutation signatures is also being evaluated in clinical trials. ARIEL2 (NCT\# 01891344) is a phase 2 study evaluating the use of rucaparib for the treatment of women with relapsed, high-grade serous or endometrioid ovarian, fallopian tube, or primary peritoneal cancer. One of the aims of this study is to define a molecular signature of HR defect in these tumors that correlates with response to rucaparib, by quantifying the extent of loss of heterozygosity ( $\mathrm{LOH}$ ) across the tumor genome (McNeish 2015).

In addition to assessing for structural rearrangement signatures, the mutational burden (total number of exome mutations) of a tumor may also be predictive of a BRCAness phenotype. Two studies of ovarian cancers showed that tumors with high mutational burdens were more responsive to platinum-based chemotherapy, suggesting that this could have some utility as a BRCAness biomarker (Birkbak et al. 2013, Lord \& Ashworth 2016).

The major drawbacks of most of these techniques used to derive mutational signatures, which will limit their role in routine clinical application, includes (1) the requirement for fresh/frozen tumor tissue for analysis, which may not always be available, (2) cost (hardware and manpower), and (3) a need for substantial bioinformatic support to analysis and interpret the data, which may not be available in most diagnostic laboratories.

\section{Functional biomarkers}

An alternative approach to identifying BRCAness would be to develop functional assays that can detect HR defects regardless of the type of genetic aberrations that are present.

One of the specific cellular hallmarks of HR is the localization of RAD51 to defined foci in the nucleus after DNA damage and this can be readily identified by immunofluorescent microscopy. Cells deficient in BRCA1/2 or other HR factors do not form RAD51 nuclear foci efficiently following DNA damage, suggesting

Published by Bioscientifica Ltd 
that this could be a functional biomarker of HR dysfunction (Michels et al. 2014, Oplustilova et al. 2012). Immunofluorescence-based detection of RAD51 foci, coupled with quantification of additional DNA repairrelated proteins, has been successfully applied to classify tumors as either HR-competent (RAD51 foci-positive) or HR-defective (RAD51 foci-negative), with a strong predictive value for chemotherapy response (Willers et al. 2009, Graeser et al. 2010, Mukhopadhyay et al. 2010). Mukhopadhyay et al. investigated RAD51 foci formation in 25 primary ovarian cancer cultures (Mukhopadhyay et al. 2010). Failure to form foci correlated with ex vivo sensitivity to rucaparib with a negative predictive value of $100 \%$ and positive predictive value of $93 \%$. The authors also reported a 50-60\% incidence of HR deficiency in sporadic ovarian cancers, which further reinforces the need for biomarkers of HR dysfunction instead of relying only on BRCA mutation status. Studies of breast cancers and AML also demonstrated that DNA damage-induced RAD51 foci can be detected in different tumor types. This approach has been applied to FFPE samples of breast cancer biopsied after neoadjuvant anthracycline therapy, where it has been shown that a low RAD51 score correlated with high histological grade, high proliferative index, and a TNBC phenotype and was predictive of complete pathological response to chemotherapy (Graeser et al. 2010). There are, however, limitations in the use of RAD51 foci as a biomarker for HR proficiency. First, RAD51 foci cannot be detected at baseline and must be induced by DNA damage such as that caused by ionizing radiation or PARPi. Second, the expression of RAD51 is restricted to the $S$ and G2 phases of proliferating cells and cannot be detected in tumor cells that are dormant or arrested in the G1 phase (Graeser et al. 2010).

Another key protein involved in DNA repair is histone H2AX, which also assembles as foci at DNA DSBs in HR competent cells, where it becomes phosphorylated to form gH2AX and creates a focus for the accumulation of DNA repair and chromatin remodeling proteins. Detection of this phosphorylation event by immunofluorescence using an antibody to gH2AX has been explored as a marker to assess the extent of DNA damage in patients (Redon et al. 2010). The use of a combination of gH2AX/RAD51 immunofluorescence was investigated in primary ovarian cancer cell cultures (Mukhopadhyay et al. 2010) and primary AML cultures (Gaymes et al. 2009), where it has been demonstrated that raised gH2AX and decreased RAD51 foci expression predict for PARPi sensitivity. These techniques have been applied to both fresh and FFPE tissues and are also currently being validated in circulating tumor cells in the peripheral blood of patients as a marker to gauge response to PARPi therapy (Yap et al. 2011).

Preclinical studies of BRCA2-mutated cancer cell lines show that PARP hyperactivation is associated with sensitivity to PARPi (Gottipati et al. 2010). A surrogate for PARP activity is the detection of PAR polymers (Turner \& Ashworth 2011). High PAR levels, as assessed by western blotting or immunohistochemistry, have been shown to predict sensitivity of human cancer cells to PARPi in vitro and in vivo and may be used to predict sensitivity to PARPi (Ji et al. 2011, Michels et al. 2013).

\section{Other biomarkers}

Other non-HR-related proteins whose function can impact HR may also contribute to 'BRCAness'. The mitotic serine/threonine kinase Aurora A is frequently amplified in cancer. In preclinical models, overexpression of Aurora A impairs RAD51 recruitment, thus disabling DSB repair and sensitizing cells to PARP inhibition (Michels et al. 2014).

Aberrations in the PI3 kinase/AKT/mTOR pathways, such as PTEN loss or activating PI3KCA mutations, may also correlate with PARPi sensitivity. PI3K inhibition has been reported to decrease the expression of BRCA1 and $B R C A 2$, thereby disabling HR-mediated repair and sensitizing BRCA wild-type TNBC cells and xenografts to PARP inhibition (Ibrahim et al. 2012). PTEN is a tumor suppressor gene that inactivates the PI3K/AKT pathway. Loss of PTEN function through mutations, deletions, or promoter hypermethylation occurs in several cancer types. Loss of PTEN has been postulated to result in HR dysfunction (Mendes-Pereira et al. 2009). Shen et al. reported that PTEN depletion impairs HR-driven repair by decreasing the expression of RAD51 (Shen et al. 2007). Increased PARPi sensitivity was demonstrated in cell line studies and xenograft models with PTEN mutation (Mendes-Pereira et al. 2009). There is also clinical evidence that PARPi may have a therapeutic utility in PTEN-deficient endometrial cancer (Dedes et al. 2010, Forster et al. 2011). However, results from a study on prostate cancers failed to show any significant correlation between PTEN status and sensitivity to PARPi or with the expression of genes associated with HR (Fraser et al. 2012).

ETS gene fusions are present in several cancer types, including Ewing's sarcoma and prostate cancer. ETS is a transcription factor with a high number of $B R C A 1 / 2$ binding motifs and may repress the BRCA promoter upon its activation by the mitogen-activated protein

Published by Bioscientifica Ltd 
kinase pathway (Sharrocks 2001, Baker et al. 2003). Gene fusion between the ERG (a member of the ETS family) proto-oncogene and TMPRSS2 promoter is observed in approximately 50\% of prostate cancers and results in aberrant androgen-dependent ERG expression (Tan et al. 2014) and promotes carcinogenesis (Tomlins et al. 2005). Preclinical studies have shown that PARP1 directly interacts with ERG to inhibit ETS gene fusion protein activity. In turn, inhibition of PARP1 reduces ETS-positive, but not ETS-negative, prostate cancer xenograft growth (Brenner et al. 2011). PARPi have also demonstrated anti-tumor activity in the treatment of Ewing's sarcoma in xenograft and cell lines studies (Brenner et al. 2012). More studies will be needed to validate the clinical predictive value of ETS gene fusions.

\section{Future directions}

The advent of new molecular profiling techniques has led to a greater understanding of cancer biology. It is increasingly evident that aside from the traditional clinicopathological classification of tumors, their unique molecular characteristics do allow them to be further stratified according to their genetic profile. This has been illustrated by the various studies that have been performed to identify tumors, other than those with BRCA1/2 mutations, which may response to PARP inhibition. However, many questions remain to be addressed. First, it is still uncertain what constitutes the best predictor of response to this group of drugs. Most clinical trials are recruiting patients based on pathological subtypes, e.g., TNBC and HGOSC, or have included $B R C A$ mutation analysis (germ line and/or somatic) as part of the selection criteria. Few have incorporated other biomarker testing such as other HR gene defects, as part of their enrolment requirements. However, there are clinical trials that have included biomarker analysis as part of their outcome measures and it is hopeful that results from these studies may help shed more light as to which additional biomarkers should be incorporated for future trials. Thus at present, although it appears that $B R C A$ remains the top candidate biomarker that should be tested to assess for PARPi response, it is highly plausible that this list will be expanded in future. Second, there is also no clear evidence as to what drives PARPi response in tumors without a mutation in a canonical HR repair gene. As PARP proteins have mechanisms of action beyond DNA repair, the benefits of PARPi are likely not going to be just confined to BRCA or even BRCAness-associated tumors. Knowledge of other mechanistic properties of
PARPi will also influence the choice of combination therapy in different cancer types. Lastly, a more in-depth understanding of the mechanisms of drug resistance is needed, as it is uncertain whether these mechanisms may differ depending on which BRCAness gene is involved or whether cross-resistance to other DNA damaging agents can occur. This again will affect the choice of combination therapy and the sequence in which these drugs should be administered.

PARPi have been yielding promising results in several clinical trials. They have been employed both as monotherapy and in combination therapy with radiation, chemotherapeutic agents, as well as other molecularly targeted agents, for several different cancer types, and have demonstrated a relatively good safety profile. The identification and validation of predictive biomarkers of response to PARPi is an important area of ongoing research, which will lead to wider clinical applications for these drugs. However, the incorporation of biomarker testing into routine clinical diagnostics also presents significant challenges. Undoubtedly, there will be more practical requirements for assays used in the clinical setting than those used for research purposes only. These tests should be readily reproducible, feasible using standard equipment, cost-effective, and can be completed in an appropriate time frame for them to be clinically relevant. It will also be an advantage if the test can be performed using FFPE tissue, as this is the material routinely available in pathology laboratories. Some centers have incorporated $B R C A$ testing (germ line and/or somatic) as part of their clinical workflow, using methods discussed previously. However, as more biomarkers are added to the list, single gene testing will undoubtedly prove to be less attractive compared with multiplex assays such as panel testing that allows for multiple genes to be interrogated simultaneously in a clinically relevant time frame. We envision that future testing strategies will adopt the latter approach to allow for more efficient and cost-effective testing. Importantly, this approach will also allow for the incorporation of predictors of drug resistance, which will help refine the selection of patients likely to respond to these therapeutic agents.

\section{Declaration of interest}

No author had any financial or personal relationships that could inappropriately influence or bias this work.

\section{Funding}

This research did not receive any specific grant from any funding agency in the public, commercial, or not-for-profit sector.

Published by Bioscientifica Ltd. 
Acknowledgments

$\mathrm{J} \mathrm{N}$ is a recipient of the National Medical Research Council (NMRC) Transition Award.

\section{References}

Abkevich V, Timms KM, Hennessy BT, Potter J, Carey MS, Meyer LA, Smith-McCune K, Broaddus R, Lu KH, Chen J, et al. 2012 Patterns of genomic loss of heterozygosity predict homologous recombination repair defects in epithelial ovarian cancer. British Journal of Cancer 107 1776-1782. (doi:10.1038/bjc.2012.451)

Alexandrov LB, Nik-Zainal S, Wedge DC, Aparicio SA, Behjati S, Biankin AV, Bignell GR, Bolli N, Borg A, Borresen-Dale AL, et al. 2013 Signatures of mutational processes in human cancer. Nature 500 415-421. (doi:10.1038/nature12477)

Alsop K, Fereday S, Meldrum C, deFazio A, Emmanuel C, George J, Dobrovic A, Birrer MJ, Webb PM, Stewart C, et al. 2012 BRCA mutation frequency and patterns of treatment response in BRCA mutation-positive women with ovarian cancer: a report from the Australian Ovarian Cancer Study Group. Journal of Clinical Oncology 30 2654-2663. (doi:10.1200/JCO.2011.39.8545)

Ashworth A 2008 A synthetic lethal therapeutic approach: poly(ADP) ribose polymerase inhibitors for the treatment of cancers deficient in DNA double-strand break repair. Journal of Clinical Oncology 26 3785-3790. (doi:10.1200/JCO.2008.16.0812)

Audeh MW, Carmichael J, Penson RT, Friedlander M, Powell B, Bell-McGuinn KM, Scott C, Weitzel JN, Oaknin A, Loman N, et al. 2010 Oral poly(ADP-ribose) polymerase inhibitor olaparib in patients with BRCA1 or BRCA2 mutations and recurrent ovarian cancer: a proof-of-concept trial. Lancet 376 245-251. (doi:10.1016/ S0140-6736(10)60893-8)

Baker KM, Wei G, Schaffner AE \& Ostrowski MC 2003 Ets-2 and components of mammalian SWI/SNF form a repressor complex that negatively regulates the BRCA1 promoter. Journal of Biological Chemistry 278 17876-17884. (doi:10.1074/jbc.M209480200)

Baldwin RL, Nemeth E, Tran H, Shvartsman H, Cass I, Narod S \& Karlan BY 2000 BRCA1 promoter region hypermethylation in ovarian carcinoma: a population-based study. Cancer Research 60 5329-5333.

Barber LJ, Sandhu S, Chen L, Campbell J, Kozarewa I, Fenwick K, Assiotis I, Rodrigues DN, Reis Filho JS, Moreno V, et al. 2013 Secondary mutations in BRCA2 associated with clinical resistance to a PARP inhibitor. Journal of Pathology 229 422-429. (doi:10.1002/path.4140)

Beltran H, Yelensky R, Frampton GM, Park K, Downing SR, MacDonald TY, Jarosz M, Lipson D, Tagawa ST, Nanus DM, et al. 2013 Targeted next-generation sequencing of advanced prostate cancer identifies potential therapeutic targets and disease heterogeneity. European Urology 63 920-926. (doi:10.1016/j.eururo.2012.08.053)

Biankin AV, Waddell N, Kassahn KS, Gingras MC, Muthuswamy LB, Johns AL, Miller DK, Wilson PJ, Patch AM, Wu J, et al. 2012 Pancreatic cancer genomes reveal aberrations in axon guidance pathway genes. Nature 491 399-405. (doi:10.1038/nature11547)

Birkbak NJ, Wang ZC, Kim JY, Eklund AC, Li Q, Tian R, BowmanColin C, Li Y, Greene-Colozzi A, Iglehart JD, et al. 2012 Telomeric allelic imbalance indicates defective DNA repair and sensitivity to DNA-damaging agents. Cancer Discovery 2 366-375. (doi:10.1158/ 2159-8290.CD-11-0206)

Birkbak NJ, Kochupurakkal B, Izarzugaza JM, Eklund AC, Li Y, Liu J, Szallasi Z, Matulonis UA, Richardson AL, Iglehart JD, et al. 2013 Tumor mutation burden forecasts outcome in ovarian cancer with BRCA1 or BRCA2 mutations. PLOS ONE 8 e80023. (doi:10.1371/ journal.pone.0080023)

Bouwman P, Aly A, Escandell JM, Pieterse M, Bartkova J, van der Gulden H, Hiddingh S, Thanasoula M, Kulkarni A, Yang Q, et al. 2010 53BP1 loss rescues BRCA1 deficiency and is associated with triple-negative and BRCA-mutated breast cancers Nature Structural \& Molecular Biology 17 688-695. (doi:10.1038/ nsmb.1831)

Brenner JC, Ateeq B, Li Y, Yocum AK, Cao Q, Asangani IA, Patel S, Wang X, Liang H, Yu J, et al. 2011 Mechanistic rationale for inhibition of poly(ADP-ribose) polymerase in ETS gene fusionpositive prostate cancer. Cancer Cell 19 664-678. (doi:10.1016/ j.ccr.2011.04.010)

Brenner JC, Feng FY, Han S, Patel S, Goyal SV, Bou-Maroun LM, Liu M, Lonigro R, Prensner JR, Tomlins SA, et al. 2012 PARP-1 inhibition as a targeted strategy to treat Ewing's sarcoma. Cancer Research $\mathbf{7 2}$ 1608-1613. (doi:10.1158/0008-5472.CAN-11-3648)

Brody LC \& Biesecker BB 1998 Breast cancer susceptibility genes. BRCA1 and BRCA2. Medicine 77 208-226. (doi:10.1097/00005792199805000-00006)

Brose MS, Rebbeck TR, Calzone KA, Stopfer JE, Nathanson KL \& Weber BL 2002 Cancer risk estimates for BRCA1 mutation carriers identified in a risk evaluation program. Journal of the National Cancer Institute 94 1365-1372. (doi:10.1093/jnci/94.18.1365)

Brown R, Timms K, Paul J, Hughes E, El-Bahrawy M, Steel JH, Kalva S, Liu X, Wang Y, Rama NR, et al. 2015 Homologous recombination (HR) deficiency, tumor BRCA1/2 mutations (tmBRCA) and association with response and outcome following platinum monotherapy in high grade serous ovarian cancer (HGSOC). Journal of Clinical Oncology 335576.

Bryant HE, Schultz N, Thomas HD, Parker KM, Flower D, Lopez E, Kyle S, Meuth M, Curtin NJ \& Helleday T 2005 Specific killing of BRCA2-deficient tumours with inhibitors of poly(ADP-ribose) polymerase. Nature 434 913-917. (doi:10.1038/nature03443)

Bunting SF, Callen E, Wong N, Chen HT, Polato F, Gunn A, Bothmer A, Feldhahn N, Fernandez-Capetillo O, Cao L, et al. 2010 53BP1 inhibits homologous recombination in Brca1-deficient cells by blocking resection of DNA breaks. Cell 141 243-254. (doi:10.1016/ j.cell.2010.03.012)

Byrne TJ, Reece MT, Adams LA, Lane MA \& Cohn GM 2000 An antibody assay predictive of BRCA1 mutations in ovarian tumors and normal tissue. Oncology Reports 7 949-953.

Cancer Genome Atlas Research Network 2011 Integrated genomic analyses of ovarian carcinoma. Nature 474 609-615. (doi:10.1038/ nature10166)

Cancer Genome Atlas Research Network 2012 Comprehensive molecular portraits of human breast tumours. Nature 490 61-70. (doi:10.1038/ nature11412)

Catteau A, Harris WH, Xu CF \& Solomon E 1999 Methylation of the BRCA1 promoter region in sporadic breast and ovarian cancer: correlation with disease characteristics. Oncogene 18 1957-1965. (doi:10.1038/sj.onc.1202509)

D'Andrea AD \& Grompe M 2003 The Fanconi anaemia/BRCA pathway. Nature Reviews. Cancer 3 23-34. (doi:10.1038/nrc970)

Daemen A, Wolf DM, Korkola JE, Griffith OL, Frankum JR, Brough R, Jakkula LR, Wang NJ, Natrajan R, Reis-Filho JS, et al. 2012 Cross-platform pathway-based analysis identifies markers of response to the PARP inhibitor olaparib. Breast Cancer Research and Treatment 135 505-517. (doi:10.1007/s10549-012-2188-0)

Davis AJ \& Chen DJ 2013 DNA double strand break repair via nonhomologous end-joining. Translational Cancer Research 2 130-143. (doi:10.3978/j.issn.2218-676X.2013.04.02)

Dedes KJ, Wetterskog D, Mendes-Pereira AM, Natrajan R, Lambros MB, Geyer FC, Vatcheva R, Savage K, Mackay A, Lord CJ, et al. 2010 PTEN deficiency in endometrioid endometrial adenocarcinomas predicts sensitivity to PARP inhibitors. Science Translational Medicine 2 53ra75. (doi:10.1126/scitranslmed.3001538)

Dedes KJ, Wilkerson PM, Wetterskog D, Weigelt B, Ashworth A \& Reis-Filho JS 2011 Synthetic lethality of PARP inhibition in cancers lacking BRCA1 and BRCA2 mutations. Cell Cycle 10 1192-1199. (doi:10.4161/cc.10.8.15273) 
Deng CX 2006 BRCA1: cell cycle checkpoint, genetic instability, DNA damage response and cancer evolution. Nucleic Acids Research 34 1416-1426. (doi:10.1093/nar/gk1010)

Do K \& Chen AP 2013 Molecular pathways: targeting PARP in cancer treatment. Clinical Cancer Research 19 977-984. (doi:10.1158/ 1078-0432.CCR-12-0163)

Edwards SL, Brough R, Lord CJ, Natrajan R, Vatcheva R, Levine DA, Boyd J, Reis-Filho JS \& Ashworth A 2008 Resistance to therapy caused by intragenic deletion in BRCA2. Nature 451 1111-1115. (doi:10.1038/nature06548)

El-Khamisy SF, Masutani M, Suzuki H \& Caldecott KW 2003 A requirement for PARP-1 for the assembly or stability of XRCC1 nuclear foci at sites of oxidative DNA damage. Nucleic Acids Research 31 5526-5533. (doi:10.1093/nar/gkg761)

Ellison G, Huang S, Carr H, Wallace A, Ahdesmaki M, Bhaskar S \& Mills J 2015 A reliable method for the detection of BRCA1 and BRCA2 mutations in fixed tumour tissue utilising multiplex PCR-based targeted next generation sequencing. BMC Clinical Pathology 15 5. (doi:10.1186/s12907-015-0004-6)

Esteller M, Silva JM, Dominguez G, Bonilla F, Matias-Guiu X, Lerma E, Bussaglia E, Prat J, Harkes IC, Repasky EA, et al. 2000 Promoter hypermethylation and BRCA1 inactivation in sporadic breast and ovarian tumors. Journal of the National Cancer Institute 92 564-569. (doi:10.1093/jnci/92.7.564)

Farmer H, McCabe N, Lord CJ, Tutt AN, Johnson DA, Richardson TB, Santarosa M, Dillon KJ, Hickson I, Knights C, et al. 2005 Targeting the DNA repair defect in BRCA mutant cells as a therapeutic strategy. Nature 434 917-921. (doi:10.1038/nature03445)

Feliubadalo L, Lopez-Doriga A, Castellsague E, del Valle J, Menendez M, Tornero E, Montes E, Cuesta R, Gomez C, Campos O, et al. 2013 Next-generation sequencing meets genetic diagnostics: development of a comprehensive workflow for the analysis of BRCA1 and BRCA2 genes. European Journal of Human Genetics 21 864-870. (doi:10.1038/ejhg.2012.270)

Fong PC, Boss DS, Yap TA, Tutt A, Wu P, Mergui-Roelvink M, Mortimer P, Swaisland H, Lau A, O'Connor MJ, et al. 2009 Inhibition of poly(ADP-ribose) polymerase in tumors from BRCA mutation carriers. New England Journal of Medicine 361 123-134. (doi:10.1056/NEJMoa0900212)

Fong PC, Yap TA, Boss DS, Carden CP, Mergui-Roelvink M, Gourley C, De Greve J, Lubinski J, Shanley S, Messiou C, et al. 2010 Poly(ADP)ribose polymerase inhibition: frequent durable responses in BRCA carrier ovarian cancer correlating with platinum-free interval. Journal of Clinical Oncology 28 2512-2519. (doi:10.1200/JCO.2009.26.9589)

Foster KA, Harrington P, Kerr J, Russell P, DiCioccio RA, Scott IV, Jacobs I, Chenevix-Trench G, Ponder BA \& Gayther SA 1996 Somatic and germline mutations of the BRCA2 gene in sporadic ovarian cancer. Cancer Research 56 3622-3625.

Forster MD, Dedes KJ, Sandhu S, Frentzas S, Kristeleit R, Ashworth A, Poole CJ, Weigelt B, Kaye SB \& Molife LR 2011 Treatment with olaparib in a patient with PTEN-deficient endometrioid endometrial cancer. Nature Reviews. Clinical Oncology 8 302-306. (doi:10.1038/nrclinonc.2011.42)

Fraser M, Zhao H, Luoto KR, Lundin C, Coackley C, Chan N, Joshua AM, Bismar TA, Evans A, Helleday T, et al. 2012 PTEN deletion in prostate cancer cells does not associate with loss of RAD51 function: implications for radiotherapy and chemotherapy. Clinical Cancer Research 18 1015-1027. (doi:10.1158/1078-0432.CCR-11-2189)

Garg K, Levine DA, Olvera N, Dao F, Bisogna M, Secord AA, Berchuck A, Cerami E, Schultz N \& Soslow RA 2013 BRCA1 immunohistochemistry in a molecularly characterized cohort of ovarian high-grade serous carcinomas. American Journal of Surgical Pathology 37 138-146. (doi:10.1097/PAS.0b013e31826cabbd)

Gaymes TJ, Shall S, MacPherson LJ, Twine NA, Lea NC, Farzaneh F \& Mufti GJ 2009 Inhibitors of poly ADP-ribose polymerase (PARP) induce apoptosis of myeloid leukemic cells: potential for therapy of myeloid leukemia and myelodysplastic syndromes. Haematologica 94 638-646. (doi:10.3324/haematol.2008.001933)

Geisler JP, Hatterman-Zogg MA, Rathe JA \& Buller RE 2002 Frequency of BRCA1 dysfunction in ovarian cancer. Journal of the National Cancer Institute 94 61-67. (doi:10.1093/jnci/94.1.61)

Gelmon KA, Tischkowitz M, Mackay H, Swenerton K, Robidoux A, Tonkin K, Hirte H, Huntsman D, Clemons M, Gilks B, et al. 2011 Olaparib in patients with recurrent high-grade serous or poorly differentiated ovarian carcinoma or triple-negative breast cancer: a phase 2, multicentre, open-label, non-randomised study. Lancet Oncology 12 852-861. (doi:10.1016/S1470-2045(11)70214-5)

George A 2015 UK BRCA mutation testing in patients with ovarian cancer. British Journal of Cancer 113 Suppl 1 S17-S21. (doi:10.1038/ bjc.2015.396)

Gonzalez-Angulo AM, Timms KM, Liu S, Chen H, Litton JK, Potter J, Lanchbury JS, Stemke-Hale K, Hennessy BT, Arun BK, et al. 2011 Incidence and outcome of BRCA mutations in unselected patients with triple receptor-negative breast cancer. Clinical Cancer Research 17 1082-1089. (doi:10.1158/1078-0432.CCR-10-2560)

Gottipati P, Vischioni B, Schultz N, Solomons J, Bryant HE, Djureinovic T, Issaeva N, Sleeth K, Sharma RA \& Helleday T 2010 Poly(ADP-ribose) polymerase is hyperactivated in homologous recombination-defective cells. Cancer Research 70 5389-5398. (doi:10.1158/0008-5472.CAN-09-4716)

Graeser M, McCarthy A, Lord CJ, Savage K, Hills M, Salter J, Orr N, Parton M, Smith IE, Reis-Filho JS, et al. 2010 A marker of homologous recombination predicts pathologic complete response to neoadjuvant chemotherapy in primary breast cancer. Clinical Cancer Research 16 6159-6168. (doi:10.1158/1078-0432. CCR-10-1027)

Grushko TA, Dignam JJ, Das S, Blackwood AM, Perou CM, Ridderstrale KK, Anderson KN, Wei MJ, Adams AJ, Hagos FG, et al. 2004 MYC is amplified in BRCA1-associated breast cancers. Clinical Cancer Resarch 10 499-507. (doi:10.1158/1078-0432.CCR-0976-03)

Gunderson CC \& Moore KN 2015 BRACAnalysis CDx as a companion diagnostic tool for Lynparza. Expert Review of Molecular Diagnostics 15 1111-1116. (doi:10.1586/14737159.2015.1078238)

Haince JF, Kozlov S, Dawson VL, Dawson TM, Hendzel MJ, Lavin MF \& Poirier GG 2007 Ataxia telangiectasia mutated (ATM) signaling network is modulated by a novel poly(ADP-ribose)-dependent pathway in the early response to DNA-damaging agents. Journal of Biological Chemistry 282 16441-16453. (doi:10.1074/jbc. M608406200)

Haince JF, McDonald D, Rodrigue A, Dery U, Masson JY, Hendzel MJ \& Poirier GG 2008 PARP1-dependent kinetics of recruitment of MRE11 and NBS1 proteins to multiple DNA damage sites. Journal of Biological Chemistry 283 1197-1208. (doi:10.1074/jbc.M706734200)

Harismendy O, Ng PC, Strausberg RL, Wang X, Stockwell TB, Beeson KY, Schork NJ, Murray SS, Topol EJ, Levy S, et al. 2009 Evaluation of next generation sequencing platforms for population targeted sequencing studies. Genome Biology 10 R32. (doi:10.1186/gb-2009-10-3-r32)

Helleday T 2011 The underlying mechanism for the PARP and BRCA synthetic lethality: clearing up the misunderstandings. Molecular Oncology 5 387-393. (doi:10.1016/j.molonc.2011.07.001)

Hennessy BT, Timms KM, Carey MS, Gutin A, Meyer LA, Flake DD 2nd, Abkevich V, Potter J, Pruss D, Glenn P, et al. 2010 Somatic mutations in BRCA1 and BRCA2 could expand the number of patients that benefit from poly (ADP ribose) polymerase inhibitors in ovarian cancer. Journal of Clinical Oncology 28 3570-3576. (doi:10.1200/ JCO.2009.27.2997)

Hernan I, Borras E, de Sousa Dias M, Gamundi MJ, Mane B, Llort G, Agundez JA, Blanca M \& Carballo M 2012 Detection of genomic variations in BRCA1 and BRCA2 genes by long-range PCR and next-generation sequencing. Journal of Molecular Diagnostics 14 286-293. (doi:10.1016/j.jmoldx.2012.01.013) 
Hilton JL, Geisler JP, Rathe JA, Hattermann-Zogg MA, DeYoung B \& Buller RE 2002 Inactivation of BRCA1 and BRCA2 in ovarian cancer. Journal of the National Cancer Institute 94 1396-1406. (doi:10.1093/ jnci/94.18.1396)

Hoeijmakers JH 2001 Genome maintenance mechanisms for preventing cancer. Nature 411 366-374. (doi:10.1038/35077232)

Hottiger MO, Hassa PO, Luscher B, Schuler H \& Koch-Nolte F 2010 Toward a unified nomenclature for mammalian ADP-ribosyltransferases. Trends in Biochemical Sciences 35 208-219. (doi:10.1016/j.tibs.2009.12.003)

Houtgraaf JH, Versmissen J \& van der Giessen WJ 2006 A concise review of DNA damage checkpoints and repair in mammalian cells. Cardiovascular Revascularization Medicine 7 165-172. (doi:10.1016/ j.carrev.2006.02.002)

Hughes-Davies L, Huntsman D, Ruas M, Fuks F, Bye J, Chin SF, Milner J, Brown LA, Hsu F, Gilks B, et al. 2003 EMSY links the BRCA2 pathway to sporadic breast and ovarian cancer. Cell 115 523-535. (doi:10.1016/S0092-8674(03)00930-9)

Ibragimova I \& Cairns P 2011 Assays for hypermethylation of the BRCA1 gene promoter in tumor cells to predict sensitivity to PARP-inhibitor therapy. Methods in Molecular Biology 780 277-291. (doi:10.1007/978-1-61779-270-0)

Ibrahim YH, Garcia-Garcia C, Serra V, He L, Torres-Lockhart K, Prat A, Anton P, Cozar P, Guzman M, Grueso J, et al. 2012 PI3K inhibition impairs BRCA1/2 expression and sensitizes BRCA-proficient triple-negative breast cancer to PARP inhibition. Cancer Discovery 2 1036-1047. (doi:10.1158/2159-8290.CD-11-0348)

Jaspers JE, Kersbergen A, Boon U, Sol W, van Deemter L, Zander SA Drost R, Wientjens E, Ji J, Aly A, et al. 2013 Loss of 53BP1 causes PARP inhibitor resistance in Brca1-mutated mouse mammary tumors. Cancer Discovery 3 68-81. (doi:10.1158/2159-8290.CD-12-0049)

Ji J, Kinders RJ, Zhang Y, Rubinstein L, Kummar S, Parchment RE, Tomaszewski JE \& Doroshow JH 2011 Modeling pharmacodynamic response to the poly(ADP-Ribose) polymerase inhibitor ABT-888 in human peripheral blood mononuclear cells. PLoS ONE 6 e26152. (doi:10.1371/journal.pone.0026152)

Johnson N, Johnson SF, Yao W, Li YC, Choi YE, Bernhardy AJ, Wang Y, Capelletti M, Sarosiek KA, Moreau LA, et al. 2013 Stabilization of mutant BRCA1 protein confers PARP inhibitor and platinum resistance. PNAS 110 17041-17046. (doi:10.1073/pnas.1305170110)

Jones PA \& Baylin SB 2002 The fundamental role of epigenetic events in cancer. Nature Reviews. Genetics 3 415-428. (doi:10.1038/nrg816)

Joosse SA, van Beers EH, Tielen IH, Horlings H, Peterse JL, Hoogerbrugge N, Ligtenberg MJ, Wessels LF, Axwijk P, Verhoef S, et al. 2009 Prediction of BRCA1-association in hereditary nonBRCA1/2 breast carcinomas with array-CGH. Breast Cancer Research and Treatment 116 479-489. (doi:10.1007/s10549-008-0117-z)

Kaufman B, Shapira-Frommer R, Schmutzler RK, Audeh MW Friedlander M, Balmana J, Mitchell G, Fried G, Stemmer SM, Hubert A, et al. 2015 Olaparib monotherapy in patients with advanced cancer and a germline BRCA1/2 mutation. Journal of Clinical Oncology 33 244-250. (doi:10.1200/JCO.2014.56.2728)

Kim G, Ison G, McKee AE, Zhang H, Tang S, Gwise T, Sridhara R, Lee E, Tzou A, Philip R, et al. 2015 FDA approval summary: olaparib monotherapy in patients with deleterious germline BRCA-mutated advanced ovarian cancer treated with three or more lines of chemotherapy. Clinical Cancer Research 21 4257-4261. (doi:10.1158/1078-0432.CCR-15-0887)

Kinsella TJ 2009 Understanding DNA damage response and DNA repair pathways: applications to more targeted cancer therapeutics. Seminars in Oncology 36 S42-51. (doi:10.1053/j.seminoncol.2009.02.004)

Konstantinopoulos PA, Spentzos D, Karlan BY, Taniguchi T, Fountzilas E, Francoeur N, Levine DA \& Cannistra SA 2010 Gene expression profile of BRCAness that correlates with responsiveness to chemotherapy and with outcome in patients with epithelial ovarian cancer. Journal of Clinical Oncology 28 3555-3561. (doi:10.1200/JCO.2009.27.5719)
Larsen MJ, Kruse TA, Tan Q, Laenkholm AV, Bak M, Lykkesfeldt AE, Sorensen KP, Hansen TV, Ejlertsen B, Gerdes AM, et al. 2013 Classifications within molecular subtypes enables identification of BRCA1/BRCA2 mutation carriers by RNA tumor profiling. PLoS ONE 8 e64268. (doi:10.1371/journal.pone.0064268)

Ledermann J, Harter P, Gourley C, Friedlander M, Vergote I, Rustin G, Scott CL, Meier W, Shapira-Frommer R, Safra T, et al. 2014 Olaparib maintenance therapy in patients with platinum-sensitive relapsed serous ovarian cancer: a preplanned retrospective analysis of outcomes by BRCA status in a randomised phase 2 trial. Lancet Oncology 15 852-861. (doi:10.1016/S1470-2045(14)70228-1)

Leongamornlert D, Mahmud N, Tymrakiewicz M, Saunders E, Dadaev T, Castro E, Goh C, Govindasami K, Guy M, O’Brien L, et al. 2012 Germline BRCA1 mutations increase prostate cancer risk. British Journal of Cancer 106 1697-1701. (doi:10.1038/bjc.2012.146)

Lesnock JL, Darcy KM, Tian C, Deloia JA, Thrall MM, Zahn C, Armstrong DK, Birrer MJ \& Krivak TC 2013 BRCA1 expression and improved survival in ovarian cancer patients treated with intraperitoneal cisplatin and paclitaxel: a Gynecologic Oncology Group Study. British Journal of Cancer 108 1231-1237. (doi:10.1038/bjc.2013.70)

Lips EH, Laddach N, Savola SP, Vollebergh MA, Oonk AM, Imholz AL, Wessels LF, Wesseling J, Nederlof PM \& Rodenhuis S 2011a Quantitative copy number analysis by Multiplex Ligationdependent Probe Amplification (MLPA) of BRCA1-associated breast cancer regions identifies BRCAness. Breast Cancer Research 13 R107. (doi:10.1186/bcr3049)

Lips EH, Mulder L, Hannemann J, Laddach N, Vrancken Peeters MT, van de Vijver MJ, Wesseling J, Nederlof PM \& Rodenhuis S 2011b Indicators of homologous recombination deficiency in breast cancer and association with response to neoadjuvant chemotherapy. Annals of Oncology 22 870-876. (doi:10.1093/annonc/mdq468)

Lord CJ \& Ashworth A 2016 BRCAness revisited. Nature Reviews. Cancer 16 110-120. (doi:10.1038/nrc.2015.21)

Loveday C, Turnbull C, Ramsay E, Hughes D, Ruark E, Frankum JR, Bowden G, Kalmyrzaev B, Warren-Perry M, Snape K, et al. 2011 Germline mutations in RAD51D confer susceptibility to ovarian cancer. Nature Genetics 43 879-882. (doi:10.1038/ng.893)

Marquard AM, Eklund AC, Joshi T, Krzystanek M, Favero F, Wang ZC, Richardson AL, Silver DP, Szallasi Z \& Birkbak NJ 2015 Pan-cancer analysis of genomic scar signatures associated with homologous recombination deficiency suggests novel indications for existing cancer drugs. Biomarker Research 3 9. (doi:10.1186/s40364-015-0033-4)

Mateo J, Carreira S, Sandhu S, Miranda S, Mossop H, Perez-Lopez R, Nava Rodrigues D, Robinson D, Omlin A, Tunariu N, et al. 2015 DNA-repair defects and olaparib in metastatic prostate cancer. New England Journal of Medicine 373 1697-1708. (doi:10.1056/ NEJMoa1506859)

Matros E, Wang ZC, Lodeiro G, Miron A, Iglehart JD \& Richardson AL 2005 BRCA1 promoter methylation in sporadic breast tumors: relationship to gene expression profiles. Breast Cancer Research Treatment 91 179-186. (doi:10.1007/s10549-004-7603-8)

McNeish IA, Oza AM, Coleman RL, Scott CL, Konecny GE, Tinker A, O'Malley DM, Brenton J, Kristeleit RS, Bell-McGuinn K, et al. 2015 Results of ARIEL2: A Phase 2 trial to prospectively identify ovarian cancer patients likely to respond to rucaparib using tumor genetic analysis. Journal of Clinical Oncology 33 abstract 5508.

Meisel JL, Hyman DM, Garg K, Zhou Q, Dao F, Bisogna M, Gao J, Schultz ND, Grisham RN, Phillips M, et al. 2014 The performance of BRCA1 immunohistochemistry for detecting germline, somatic, and epigenetic BRCA1 loss in high-grade serous ovarian cancer. Annals of Oncology 25 2372-2378. (doi:10.1093/annonc/mdu461)

Mendes-Pereira AM, Martin SA, Brough R, McCarthy A, Taylor JR, Kim JS, Waldman T, Lord CJ \& Ashworth A 2009 Synthetic lethal targeting of PTEN mutant cells with PARP inhibitors. EMBO Molecular Medicine 1 315-322. (doi:10.1002/emmm.200900041) 
Michels J, Vitale I, Galluzzi L, Adam J, Olaussen KA, Kepp O, Senovilla L, Talhaoui I, Guegan J, Enot DP, et al. 2013 Cisplatin resistance associated with PARP hyperactivation. Cancer Research $\mathbf{7 3}$ 2271-2280. (doi:10.1158/0008-5472.CAN-12-3000)

Michels J, Vitale I, Saparbaev M, Castedo M \& Kroemer G 2014 Predictive biomarkers for cancer therapy with PARP inhibitors. Oncogene 33 3894-3907. (doi:10.1038/onc.2013.352)

Mukhopadhyay A, Elattar A, Cerbinskaite A, Wilkinson SJ, Drew Y, Kyle S, Los G, Hostomsky Z, Edmondson RJ \& Curtin NJ 2010 Development of a functional assay for homologous recombination status in primary cultures of epithelial ovarian tumor and correlation with sensitivity to poly(ADP-ribose) polymerase inhibitors. Clinical Cancer Research 16 2344-2351. (doi:10.1158/1078-0432.CCR-09-2758)

Murai J, Huang SY, Das BB, Renaud A, Zhang Y, Doroshow JH, Ji J, Takeda S \& Pommier Y 2012 Trapping of PARP1 and PARP2 by clinical PARP inhibitors. Cancer Research 72 5588-5599. (doi:10.1158/0008-5472.CAN-12-2753)

Norquist B, Wurz KA, Pennil CC, Garcia R, Gross J, Sakai W, Karlan BY, Taniguchi T \& Swisher EM 2011 Secondary somatic mutations restoring BRCA1/2 predict chemotherapy resistance in hereditary ovarian carcinomas. Journal of Clinical Oncology 29 3008-3015. (doi:10.1200/JCO.2010.34.2980)

O'Sullivan CC, Moon DH, Kohn EC \& Lee JM 2014 Beyond breast and ovarian cancers: PARP inhibitors for BRCA mutation-associated and BRCA-like solid tumors. Frontiers in Oncology 4 42. (doi:10.3389/ fonc.2014.00042)

Oplustilova L, Wolanin K, Mistrik M, Korinkova G, Simkova D, Bouchal J, Lenobel R, Bartkova J, Lau A, O'Connor MJ, et al. 2012 Evaluation of candidate biomarkers to predict cancer cell sensitivity or resistance to PARP-1 inhibitor treatment. Cell Cycle 11 3837-3850. (doi:10.4161/cc.22026)

Pal T, Permuth-Wey J, Betts JA, Krischer JP, Fiorica J, Arango H, LaPolla J, Hoffman M, Martino MA, Wakeley K, et al. 2005 BRCA1 and BRCA2 mutations account for a large proportion of ovarian carcinoma cases. Cancer 104 2807-2816. (doi:10.1002/cncr.21536)

Patch AM, Christie EL, Etemadmoghadam D, Garsed DW, George J, Fereday S, Nones K, Cowin P, Alsop K, Bailey PJ, et al. 2015 Whole-genome characterization of chemoresistant ovarian cancer. Nature 521 489-494. (doi:10.1038/nature14410)

Paul I, Savage KI, Blayney JK, Lamers E, Gately K, Kerr K, Sheaff M, Arthur K, Richard DJ, Hamilton PW, et al. 2011 PARP inhibition induces BAX/BAK-independent synthetic lethality of BRCA1-deficient non-small cell lung cancer. Journal of Pathology 224 564-574. (doi:10.1002/path.2925)

Peng G, Chun-Jen Lin C, Mo W, Dai H, Park YY, Kim SM, Peng Y, Mo Q, Siwko S, Hu R, et al. 2014 Genome-wide transcriptome profiling of homologous recombination DNA repair. Nature Communications 53361

Pennington KP, Walsh T, Harrell MI, Lee MK, Pennil CC, Rendi MH, Thornton A, Norquist BM, Casadei S, Nord AS, et al. 2014 Germline and somatic mutations in homologous recombination genes predict platinum response and survival in ovarian, fallopian tube, and peritoneal carcinomas. Clinical Cancer Research 20 764-775. (doi:10.1158/1078-0432.CCR-13-2287)

Polo SE \& Jackson SP 2011 Dynamics of DNA damage response proteins at DNA breaks: a focus on protein modifications. Genes \& Development 25 409-433.

Rebbeck TR, Mitra N, Wan F, Sinilnikova OM, Healey S, McGuffog L, Mazoyer S, Chenevix-Trench G, Easton DF, Antoniou AC, et al. 2015 Association of type and location of BRCA1 and BRCA2 mutations with risk of breast and ovarian cancer. JAMA $\mathbf{3 1 3}$ 1347-1361.

Redon CE, Nakamura AJ, Zhang YW, Ji JJ, Bonner WM, Kinders RJ, Parchment RE, Doroshow JH \& Pommier Y 2010 Histone gammaH2AX and poly(ADP-ribose) as clinical pharmacodynamic biomarkers. Clinical Cancer Research 16 4532-4542. (doi:10.1158/1078-0432.CCR-10-0523)

Rice JC, Ozcelik H, Maxeiner P, Andrulis I \& Futscher BW 2000 Methylation of the BRCA1 promoter is associated with decreased BRCA1 mRNA levels in clinical breast cancer specimens. Carcinogenesis 21 1761-1765. (doi:10.1093/carcin/21.9.1761)

Rigakos G \& Razis E 2012 BRCAness: finding the Achilles heel in ovarian cancer. Oncologist 17 956-962. (doi:10.1634/ theoncologist.2012-0028)

Robinson D, Van Allen EM, Wu YM, Schultz N, Lonigro RJ, Mosquera JM, Montgomery B, Taplin ME, Pritchard CC, Attard G, et al. 2015 Integrative clinical genomics of advanced prostate cancer. Cell 161 1215-1228.

Rouleau M, Patel A, Hendzel MJ, Kaufmann SH \& Poirier GG 2010 PARP inhibition: PARP1 and beyond. Nature Reviews. Cancer 10 293-301. (doi:10.1038/nrc2812)

Ruiz A, Llort G, Yague C, Baena N, Vinas M, Torra M, Brunet A, Segui MA, Saigi E \& Guitart M 2014 Genetic testing in hereditary breast and ovarian cancer using massive parallel sequencing. BioMed Research International 2014 542541. (doi:10.1155/2014/542541)

Ruscito I, Dimitrova D, Vasconcelos I, Gellhaus K, Schwachula T, Bellati F, Zeillinger R, Benedetti-Panici P, Vergote I, Mahner S, et al. 2014 BRCA1 gene promoter methylation status in high-grade serous ovarian cancer patients - a study of the tumour Bank ovarian cancer (TOC) and ovarian cancer diagnosis consortium (OVCAD). European Journal of Cancer 50 2090-2098. (doi:10.1016/j.ejca.2014.05.001)

Sakai W, Swisher EM, Karlan BY, Agarwal MK, Higgins J, Friedman C, Villegas E, Jacquemont C, Farrugia DJ, Couch FJ, et al. 2008 Secondary mutations as a mechanism of cisplatin resistance in BRCA2-mutated cancers. Nature 451 1116-1120. (doi:10.1038/ nature06633)

Sakai W, Swisher EM, Jacquemont C, Chandramohan KV, Couch FJ, Langdon SP, Wurz K, Higgins J, Villegas E \& Taniguchi T 2009 Functional restoration of BRCA2 protein by secondary BRCA2 mutations in BRCA2-mutated ovarian carcinoma. Cancer Research 69 6381-6386. (doi:10.1158/0008-5472.CAN-09-1178)

Savage KI, Gorski JJ, Barros EM, Irwin GW, Manti L, Powell AJ, Pellagatti A, Lukashchuk N, McCance DJ, McCluggage WG, et al. 2014 Identification of a BRCA1-mRNA splicing complex required for efficient DNA repair and maintenance of genomic stability. Molecular Cell 54 445-459. (doi:10.1016/j.molcel.2014.03.021)

Schelman WR, Sandhu SK, Moreno Garcia V, Wilding G, Sun L, Toniatti C, Stroh M, Kreischer N, Carpenter CL, Molife LR, et al. 2011 First-in human trial of poly(ADP)-ribose polymerase (PARP) inhibitor MK-4827 in advanced cancer patients with anti- tumor activity in BRCA-deficient tumors and sporadic ovarian cancers Journal of Clinical Oncology 29 abstract 3102.

Schreiber V, Dantzer F, Ame JC \& de Murcia G 2006 Poly(ADP-ribose): novel functions for an old molecule. Nature Reviews: Molecular Cell Biology 7 517-528. (doi:10.1038/nrm1963)

Sharrocks AD 2001 The ETS-domain transcription factor family. Nature Reviews. Molecular Cell Biology 2 827-837. (doi:10.1038/35099076)

Shen WH, Balajee AS, Wang J, Wu H, Eng C, Pandolfi PP \& Yin Y 2007 Essential role for nuclear PTEN in maintaining chromosomal integrity. Cell 128 157-170. (doi:10.1016/j.cell.2006.11.042)

Sims D, Sudbery I, Ilott NE, Heger A \& Ponting CP 2014 Sequencing depth and coverage: key considerations in genomic analyses. Nature Reviews: Genetics 15 121-132. (doi:10.1038/nrg3642)

Sorlie T, Tibshirani R, Parker J, Hastie T, Marron JS, Nobel A, Deng S, Johnsen H, Pesich R, Geisler S, et al. 2003 Repeated observation of breast tumor subtypes in independent gene expression data sets. PNAS 100 8418-8423. (doi:10.1073/pnas.0932692100)

Stefansson OA, Jonasson JG, Johannsson OT, Olafsdottir K, Steinarsdottir M, Valgeirsdottir S \& Eyfjord JE 2009 Genomic profiling of breast tumours in relation to BRCA abnormalities and phenotypes. Breast Cancer Research 11 R47. 
Strom CE \& Helleday T 2012 Strategies for the use of poly(adenosine diphosphate ribose) polymerase (PARP) inhibitors in cancer therapy. Biomolecules 2 635-649. (doi:10.3390/biom2040635)

Tan DS, Rothermundt C, Thomas K, Bancroft E, Eeles R, Shanley S, Ardern-Jones A, Norman A, Kaye SB \& Gore ME 2008 "BRCAness" syndrome in ovarian cancer: a case-control study describing the clinical features and outcome of patients with epithelial ovarian cancer associated with BRCA1 and BRCA2 mutations. Journal of Clinical Oncology 26 5530-5536. (doi:10.1200/JCO.2008.16.1703)

Tan SH, Furusato B, Fang X, He F, Mohamed AA, Griner NB, Sood K, Saxena S, Katta S, Young D, et al. 2014 Evaluation of ERG responsive proteome in prostate cancer. Prostate 74 70-89. (doi:10.1002/ pros.22731)

Taniguchi T, Tischkowitz M, Ameziane N, Hodgson SV, Mathew CG, Joenje H, Mok SC \& D'Andrea AD 2003 Disruption of the Fanconi anemia-BRCA pathway in cisplatin-sensitive ovarian tumors. Nature Medicine 9 568-574. (doi:10.1038/nm852)

Telli ML, Timms KM, Reid JE, Hennessy B, Mills GB, Jensen KC, Szallasi Z, Barry WT, Winer EP, Tung N, et al. 2016 Homologous recombination deficiency (HRD) score predicts response to platinum-containing neoadjuvant chemotherapy in patients with triple negative breast cancer. Clinical Cancer Research [in press].

Teodoridis JM, Hall J, Marsh S, Kannall HD, Smyth C, Curto J, Siddiqui N, Gabra H, McLeod HL, Strathdee G, et al. 2005 CpG island methylation of DNA damage response genes in advanced ovarian cancer. Cancer Research 65 8961-8967. (doi:10.1158/0008-5472.CAN-05-1187)

Timms KM, Abkevich V, Hughes E, Neff C, Reid J, Morris B, Kalva S, Potter J, Tran TV, Chen J, et al. 2014 Association of BRCA1/2 defects with genomic scores predictive of DNA damage repair deficiency among breast cancer subtypes. Breast Cancer Research 16475.

Tomlins SA, Rhodes DR, Perner S, Dhanasekaran SM, Mehra R, Sun XW, Varambally S, Cao X, Tchinda J, Kuefer R, et al. 2005 Recurrent fusion of TMPRSS2 and ETS transcription factor genes in prostate cancer. Science 310 644-648. (doi:10.1126/science.1117679)

Turner NC \& Ashworth A 2011 Biomarkers of PARP inhibitor sensitivity. Breast Cancer Research and Treatment 127 283-286. (doi:10.1007/ s10549-011-1375-8)

Turner N, Tutt A \& Ashworth A 2004 Hallmarks of 'BRCAness' in sporadic cancers. Nature Reviews. Cancer 4 814-819. (doi:10.1038/ nrc1457)

Tutt A \& Ashworth A 2002 The relationship between the roles of BRCA genes in DNA repair and cancer predisposition. Trends in Molecular Medicine 8 571-576. (doi:10.1016/S1471-4914(02)02434-6)

Tutt A, Bertwistle D, Valentine J, Gabriel A, Swift S, Ross G, Griffin C, Thacker J \& Ashworth A 2001 Mutation in Brca2 stimulates error-prone homology-directed repair of DNA double-strand breaks occurring between repeated sequences. EMBO Journal 20 4704-4716. (doi:10.1093/emboj/20.17.4704)

Tutt A, Robson M, Garber JE, Domchek SM, Audeh MW, Weitzel JN, Friedlander M, Arun B, Loman N, Schmutzler RK, et al. 2010 Oral poly(ADP-ribose) polymerase inhibitor olaparib in patients with BRCA1 or BRCA2 mutations and advanced breast cancer: a proof-of-concept trial. Lancet 376 235-244. (doi:10.1016/S0140-6736(10)60892-6)

Vaz FH, Machado PM, Brandao RD, Laranjeira CT, Eugenio JS, Fernandes AH \& Andre SP 2007 Familial breast/ovarian cancer and BRCA1/2 genetic screening: the role of immunohistochemistry as an additional method in the selection of patients. Journal of Histochemistry and Cytochemistry 55 1105-1113. (doi:10.1369/ jhc.7A7209.2007)

Venkitaraman AR 2002 Cancer susceptibility and the functions of BRCA1 and BRCA2. Cell 108 171-182. (doi:10.1016/S0092-8674(02)00615-3)
Venkitaraman AR 2003 A growing network of cancer-susceptibility genes. New England Journal of Medicine 348 1917-1919. (doi:10.1056/NEJMcibr023150)

Vollebergh MA, Lips EH, Nederlof PM, Wessels LF, Schmidt MK, van Beers EH, Cornelissen S, Holtkamp M, Froklage FE, de Vries EG et al. 2011 An aCGH classifier derived from BRCA1-mutated breast cancer and benefit of high-dose platinum-based chemotherapy in HER2-negative breast cancer patients. Annals of Oncology 22 1561-1570. (doi:10.1093/annonc/mdq624)

Vollebergh MA, Lips EH, Nederlof PM, Wessels LF, Wesseling J, Vd Vijver MJ, de Vries EG, van Tinteren H, Jonkers J, Hauptmann M, et al. 2014 Genomic patterns resembling BRCA1and BRCA2-mutated breast cancers predict benefit of intensified carboplatin-based chemotherapy. Breast Cancer Research 16 R47.

Walsh T, Casadei S, Lee MK, Pennil CC, Nord AS, Thornton AM, Roeb W, Agnew KJ, Stray SM, Wickramanayake A, et al. 2011 Mutations in 12 genes for inherited ovarian, fallopian tube, and peritoneal carcinoma identified by massively parallel sequencing. PNAS 108 18032-18037. (doi:10.1073/pnas.1115052108)

Wang M, Wu W, Wu W, Rosidi B, Zhang L, Wang H \& Iliakis G 2006 PARP-1 and Ku compete for repair of DNA double strand breaks by distinct NHEJ pathways. Nucleic Acids Research 34 6170-6182. (doi:10.1093/nar/gkl840)

Wang ZC, Birkbak NJ, Culhane AC, Drapkin R, Fatima A, Tian R, Schwede M, Alsop K, Daniels KE, Piao H, et al. 2012 Profiles of genomic instability in high-grade serous ovarian cancer predict treatment outcome. Clinical Cancer Research 18 5806-5815. (doi:10.1158/1078-0432.CCR-12-0857)

Watkins JA, Irshad S, Grigoriadis A \& Tutt AN 2014 Genomic scars as biomarkers of homologous recombination deficiency and drug response in breast and ovarian cancers. Breast Cancer Research 16 211. (doi:10.1186/bcr3670)

Watkins J, Weekes D, Shah V, Gazinska P, Joshi S, Sidhu B, Gillett C, Pinder S, Vanoli F, Jasin M, et al. 2015 Genomic complexity profiling reveals that HORMAD1 overexpression contributes to homologous recombination deficiency in triple-negative breast cancers. Cancer Discovery 5 488-505. (doi:10.1158/2159-8290.CD-14-1092)

Weaver AN \& Yang ES 2013 Beyond DNA repair: additional functions of PARP-1 in cancer. Frontiers in Oncology 3290.

Wilcoxen KM, Becker M, Neff C, Abkevich V, Jones JT, Hou X, Wang Y, Hartman AR, AlHilli MM, Gutin A, et al. 2015 Use of homologous recombination deficiency (HRD) score to enrich for niraparib sensitive high grade ovarian tumors. Journal of Clinical Oncology 335532.

Willers H, Taghian AG, Luo CM, Treszezamsky A, Sgroi DC \& Powell SN 2009 Utility of DNA repair protein foci for the detection of putative BRCA1 pathway defects in breast cancer biopsies. Molecular Cancer Research 7 1304-1309. (doi:10.1158/1541-7786.MCR-09-0149)

Wu L 2008 Wrestling off RAD51: a novel role for RecQ helicases. Bioessays 30 291-295. (doi:10.1002/bies.20735)

Xia F, Taghian DG, DeFrank JS, Zeng ZC, Willers H, Iliakis G \& Powell SN 2001 Deficiency of human BRCA2 leads to impaired homologous recombination but maintains normal nonhomologous end joining. PNAS 98 8644-8649. (doi:10.1073/pnas.151253498)

Xu G, Chapman JR, Brandsma I, Yuan J, Mistrik M, Bouwman P, Bartkova J, Gogola E, Warmerdam D, Barazas M, et al. 2015 REV7 counteracts DNA double-strand break resection and affects PARP inhibition. Nature 521 541-544. (doi:10.1038/ nature14328)

Yap TA, Sandhu SK, Carden CP \& de Bono JS 2011 Poly(ADP-ribose) polymerase (PARP) inhibitors: exploiting a synthetic lethal strategy in the clinic. CA: A Cancer Journal for Clinicians 61 31-49. (doi:10.3322/caac.20095)

Received in final form 22 May 2016

Accepted 23 May 2016

Accepted Preprint published online 25 May 2016 